889
$L_{3}$ $88^{\circ}$
$L_{3}$

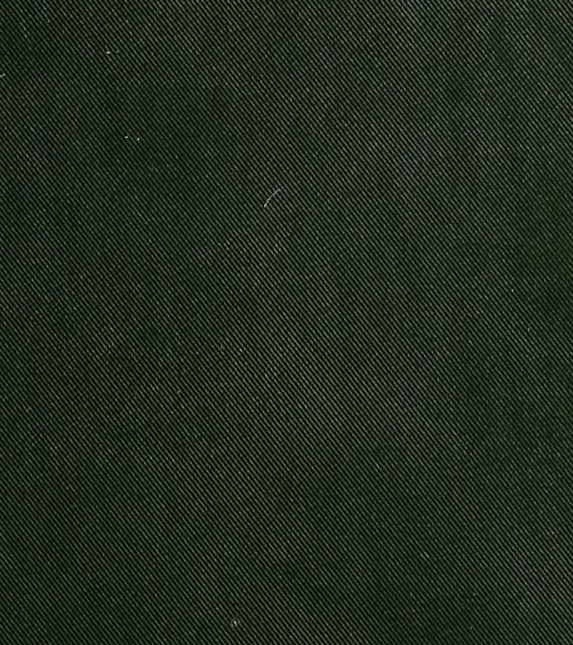

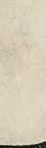

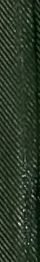

$$
\text { . }
$$

$$
\text { . }
$$

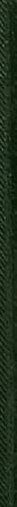




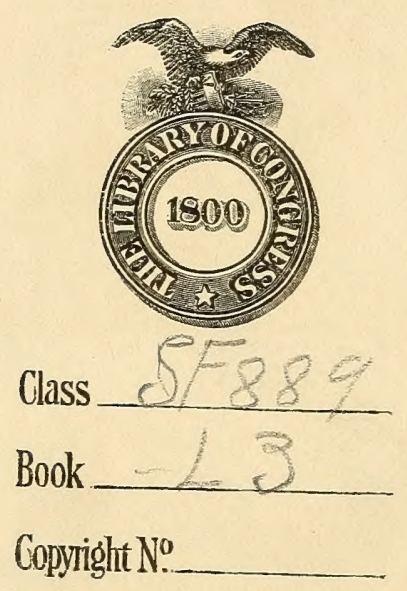

COPYRIGHT DEPOSIT. 




\section{VETERINARY MEDICINE SERIES}

No. 8

\section{ANIMAL CASTRATION}

BY

J. V. LACROIX, D.V.S.

Professor of Surgery, The Kansas City Veterinary College

\section{ILLUSTRATED}

Chicago

AMERICAN JOURNAL OF VETERINARY MEDICINE 


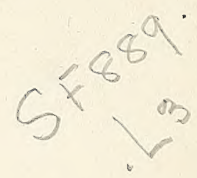

Copyraght 1915

BY

D. M. Campeell

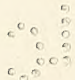

חก.T 181915

(C) $\mathrm{Cl}_{\mathrm{A}} 4141 \% 6$

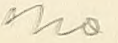




\section{PREF A CE}

This work is not intended for those unacquainted with anatomy, restraint of animals, principles of surgery and asepsis. It is assumed that the student is familiar with anatomy, and no attempt at such instruction has been made. However, anatomy is treated in sufficient detail for accurate description of the technic pertaining to the various operations considered. The reader's familiarity with the restraint of animals being presupposed, tedious recital of modes of restraint has been omitted; but the kind of restraint that will best serve any given operation has been indicated. Since a good working knowledge of the principles of surgery and asepsis is necessary to comprehend the text, frequent reminders that instruments should be boiled and the operator's hands washed, have beèn purposely avoided. The selection of instruments is a matter of individual choice or custom, and, therefore, naming the instruments required for each operation described, has been intentionally omitted.

This volume is a résumé of observations made during ten years' experience in the castration of animals. In considering the technic of operations, where more than one method is in vogue, the one that has proved the most practicable has been described.

The sections on equine umbilical hernia and cesarean operation in the sow have been included because these cases command much of the veterinarian's attention during the season of castration.

J. V. L.

October, 1915. 



\section{CONTENTS}

PAGF

List of Illustrations........................ 7

Introduction $\ldots \ldots \ldots \ldots \ldots \ldots \ldots \ldots \ldots \ldots \ldots \ldots \ldots \ldots$

PART I

Castration of Males

SECTION I.

Preliminary Measures $\ldots \ldots \ldots \ldots \ldots \ldots \ldots \ldots \ldots \ldots \ldots$

SECTION II.

Anatomy of the Structures Directly Involved.......... 23

SECTION III.

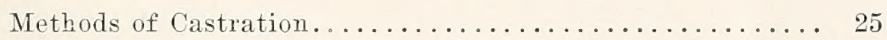

SECTION IV.

Castration of the Horse..................... 29

SECTION V.

Castration of the Bos...................... 59

SECTION VI.

Castration of Sheep........................... 73

SECTION VII.

Cestration of Swine....................... 75

\section{SECTION VIII.}

Castration of Dogs and Cats.............. 83

SECTION IX.

Castration of Birds.......................... 87 


\section{CONTENTS-Continued}

\section{PART II}

Castration of Females

\section{SECTION I.}

Vaginal Ovariotomy of the Mare............... 89

SECTION II.

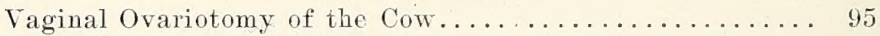

SECTION III.

Castration of Heifers............................ 97

\section{SECTION IV.}

Castration of Sows........................ 101

SECTION $V$.

Castration of the $\operatorname{Dog}$ (Spaying) . . . . . . . . . . 10

SECTION VI.

Castration of the Cat (Spaying) ............... 119

APPENDIX.

Equine Umbilical Hernia..................... 125

Cesarean Section in the Sow .................... 133

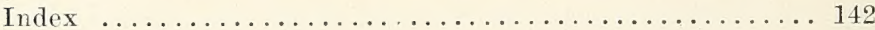




\section{ILLUSTRATIONS}

FIGURE

PARE

1. A Castrating Knife with Convex Cutting Edge...... 15

2. A Castrating Knife Having a Hooked Blade......... 16

3. Emasculator ........................ 16

4. Ecraseur ............................ 17

5. Castration of the Colt in a Standing Position....... 19

(i. Restraint for Castrating Colts................ 20

7. The "Covered Operation",................. 27

8. A Mcdification of the "Covered Operation"'........ 31

9. Restraint for Cryptorehid Castration............ 40

10. Genital Organs of the Bull................ 60

11. Castrating the Young Calf.................. 61

12. Restraint of Calf in Standing Position for Castration.. 62

13. Showing Position of Operator, Also Lines of Incision.. 63

14. Rueff's Method of Casting................. 65

15. Showing Manner of Restraint of Male Cat for Cas-

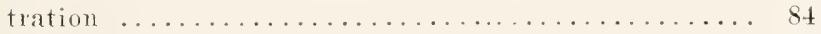

16. I Form of Hippo-Jasso................. 91

17. Restraint for spaying. . . . . . . . . . . . 100

1५. Median line Incision for Spaving.............. 108

19. The Ovary Within the Grasp of the Spaying Forceps. . 111

20. Completing the Process of Limited Torsion for Amputation of the Ovary................... 112

21. Suture for Coaptation of the Peritoneum and Abdominal Museles .......................... 113

22. Nethod of Tying Continuous Suture............. 114

23. Flank Ineision for Spaying the Cat.............. 121 



\section{INTRODUCTION}

\section{History}

Castration of animals was practiced by the ancients as there is occasional mention of it in literature, but it is doubtful if this operation was performed on animals before it was practiced on the human. There is frequent allusion to castration or to one castrated in many literary works and data on this operation as practiced upon the human subject are readily obtained.

We quote from A Reference Handbook of the Medical Sciences, Vol. II, page 710: "Castration is a very ancient practice. It was a consequence of the system of polygamy. The word Eunuch means literally having charge of the bed chamber. The Hebrew word means mutilated, and the first royal chamberlains were probably castrated men. Later the term eunuch was applied to men in all sorts of offices and it lost its original meaning."

"Herodotus relates that the castration of slaves was an industry among the Greeks. These slaves brought a high price in the markets of Ephesus. Early records of castration in China date back to 1100 B. C. Next to beheading it was at one time the most severe form of punishment."

\section{Object}

Reasons for the castrating of animals may be divided into two general classes. First, for economic purposes; making it possible to keep and work animals of both 
sexes together without difficulty, which would be impossible if the males were left entire; to regulate the reproductive numbers and thereby seek to elevate the standard of any given species; and to obviate dangers of accidents and injuries occasioned by the instinctive combat between males. The second reason for animal castration is to work for the otherwise impossible correction of certain pathological conditions, such as infectious orchitis, and in some cases of strangulated hernia of the breeding male.

Castration has a marked effect upon the conformation of animals and viewed from the economical standpoint, this result is beneficial. Conformation is materially altered, and where the animal is castrated at an early age, the type is not so strongly developed as in the case of the unaltered subject. Geldings do not possess the physical maturity of stallions, being less powerful in appearance and lacking the large, masculine facial features of the stallion. The neck is more slender, the crest somewhat undeveloped, and the muscularity of the breast and forearms is not so pronounced,-in short, the entire body partakes of a finer and more feminine type. A similar but less observable condition occurs with respect to the unsexed female. This is true, in varying degrees, of all animals.

The character of the flesh of a castrated animal is also materially different from that of the uncastrated, the flesh of the steer having a better flavor and being more tender and edible than that of a bull. This is particularly noticeable in the flesh of swine,- - the meat of the entire male $h o g$ or one castrated after attaining maturity, having a characteristic odor and being not really palatable.

The flow of milk is said to be appreciably prolonged in cows that have been spayed, but it is doubtful if 
the quality of the milk is improved in the least. In those instances where it is undesirable or inconvenient to breed milk cows, the estral period interferes materially with lactation at each regular recurrence. In such cases spaying is advisable.

The best age for castrating the various species is a much-debated question, as many circumstances govern, in a measure, the decision in different cases. It is generally conceded that a colt is best castrated between the ages of nine and twenty-four months, though some stock owners are firmly of the opinion that colts should not be altered until they are two years of age, claiming that this delay enables the animals to attain better physical development. While this may be true in certain cases, yet in the average thrifty colt, particularly of the draft breeds, the gain in certain parts of the physique is offset by pronounced undesirable characteristics which manifest themselves because of late castration. The vigorous draft colt castrated at the age of two years may possess a better developed head, neck and fore quarters than does the one operated on at a year of age, yet the croup and hind quarters of the first, are not developed in proportion to the fore quarters, there resulting an asymmetrical conformation. Because of the fact that the testicles normally descend at or soon after birth in the normal foal, in a few cases the inguinal canal remains somewhat lax and loose, making eastration of a foal during his earlier months, an unsafe procedure, as hernia and even eventration may result. L'nder average normal conditions the best age for castrating colts is between nine and twelve months. Males of the bovine species are best castrated when very young, and since the operation apparently causes the subject a minimum degree of discomfort and there is no reason for not operating 
at a very early age, it is best to select the earliest convenient time. Swine also are most successfully altered when very young. Sheep and goats are not capable of withstanding surgical interference to the same extent as cattle, and are best castrated at or about two months of age. Dogs and cats are castrated merely as a matter of domestic convenience, and in the majority of instances, since these animals are kept for pets or companions, the operation is best and easiest for the subject at or about the age of six months. In the unsexing of females, reasons for operating determine in a measure, the age most suitable. Heifers are spayed, if possible, before experiencing their first estral period, and the same is true of female swine, dogs and cats. Where the operation is done by the method of Charlier, the animal needs to attain a sufficient degree of development to enable the operator to comfortably manipulate instruments within the vaginal canal. Long deferment of this operation, however, is not likely to bring at once the desired result of absence of the sexual instinct in the previously bred female of some species.

\section{Season and Age for Castration}

The season best suited for castrating depends somewhat upon climatic conditions, existent vulnerable agencies, and customs fixed because of the element of convenience necessary in proper handling of the subjects. In those latitudes where insect life or other vulnerable agencies frequently cause an unfavorable outcome, castration should be done in the spring of the year. Where animals are sent to pasture for the spring or summer months, the operation is more conveniently done before they are turned out. In other 
instances, where screw worms do not abound, or where the subjects are somewhat unthrifty, it is best to castrate them during the early summer months. It seems hardly necessary to say that animals should not be exposed to adverse elements immediately after this operation, as exposure to long-continued cold rains tends to lower the vitality, decrease the powers of resistance and enhances the possibility of sequele. However, the fallacious theory cherished by some, that colts should not be exposed to rain directly after castration, should be emphatically disconraged. Inevitably more harm is done by the well-meaning client who shelters his recently castrated colt in an unsanitary and even filthy stall than can possibly be occasioned by the heaviest downpour of rain, provided the weather is not cold. It has been found impossible for a newly castrated colt to assume the normal recumbent position when it is kept in a stable or littered barnyard without causing contamination of the surgical wounds of the scrotum. Postoperative infections have been so caused in many instances, at the expense of the reputation of the acting veterinarian, and it therefore behooves the castrator to insist positively upon having his patient kept away from all barnyard filth until the scrotal wounds have healed completely.

In eastrating normal young animals that are kept under average conditions, no preoperative preparation is urgent. Where general anesthesia is employed in the handling of mature animals, or in the case of nervous stallions, food should be withheld for a sufficient length of time to minimize the danger of fermentation of ingesta which might be brought on by the attendant excitement. In certain pathological conditions where the operation is likely to consume con- 
siderable time, as in some cryptorchids, and in cases where general anesthesia is to be employed, animals should always be dieted before operating. Preoperative preparation of the surgical field varies with the case and the manner in which the technique is executed. Where a normal animal is castrated under average conditions, local preparation consists in washing with suitable solutions and rendering the field clean. In other cases, such as cryptorchid castration, a thorough cleansing of the surgical area with soap and water, drying the parts, and finally painting the skin with tincture of iodin, is a necessary precautionary measure. In the castration of swine and calves, if the parts are not soiled, no preoperative local cleansing is imperative. 


\section{PAR'T ONE}

\section{SECTION I}

\section{CASTRATION OF MALES PRELIMINARY MEASURES}

\section{Selection of Instruments}

In the performance of any surgical operation, every reputable surgeon has his decided preference with regard to the instruments and appliances to be used, and while it is not our purpose to recommend any particular make of instruments, we do deem it wise to call attention to the fact that there are a discov-

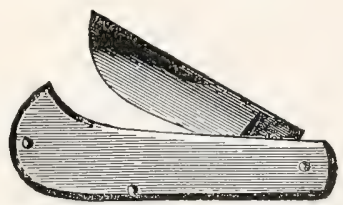

Fig. 1-A CASTRATING INIFE OF A GOOD PATTERN, HAVING A SHORT BLADE WITH CONVEX CUTTING EDGE

ered few on the market the faulty construction of which makes them very undesirable for the purpose of castration.

Especially must the instrument used for this purpose be a properly designed one and of a convenient size. Castrating knives are made of the hoe blade or hooked pattern, or equipped with a rather short blade having a very convex cutting edge, and are preferably devoid of a sharp point.

For the ablation of the testicle, the emasculator is the more widely used instrument by scientific veterinarians, and so long as it is constructed in such manner that division of the cord may be effected 
without subsequent hemorrhage, the essentials exist, and it remains a matter of choice with the operator as to which particular style of this instrument he

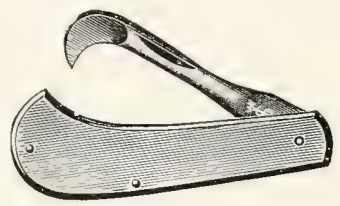

Fig. 2-A SUITABLE CASTRATING KNIFE HAVING A HOOKED BLADE

may prefer to use. The same statement is true of the ecraseur, and as these two instruments are the principal ones employed in the castrating operation, none other's will be mentioned here.

As in the case of all surgical instruments, it is most important that they be properly cared for-kept clean and dry when not in use. It is quite impossible to keep an instrument clean after the plating has become damaged. Every veterinarian should have sufficient pride in the appearance of his equipment to keep

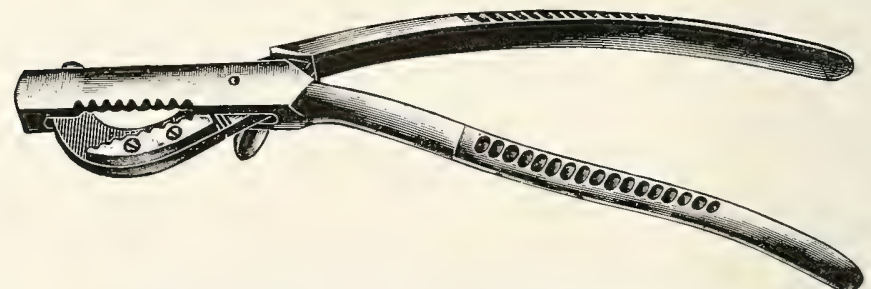

Fig. 3-A VERY GOOD STYLE OF EMASCULATOR WITH EXTRA ATTACHMENT TO INSURE HEMOSTASIS

it in good condition, even though it were not urgent to do so in the case of castrating instruments, to prevent possible infection, and only the practitioners who have this innate pride will tend to raise the standard of their profession. Castrating instruments should be 
boiled daily when regularty used and should be kepl wrapped in a clean, sterile towel, and not loosely thrown in the soiled and more or less contaminated emergency bag. In field work the average client will inwardly, if not outwardly, appreciate the pains taken by the serupulously exacting operator, even though he is put to some effort to procure a clean pail or basin and sterile towels for the convenience of the veterinarian,

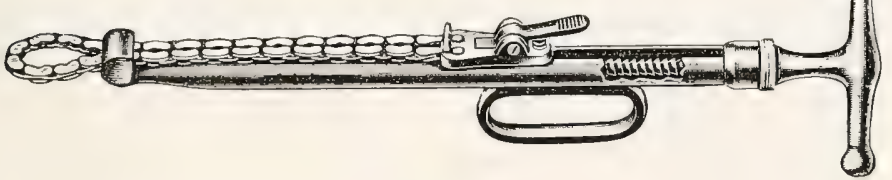

Fig. 4-A SUBSTANTIAL ECRASEUR OF THE "QUICK-CHAIN" TYPE

when the client understands that such precautions are taken for the sole purpose of lessening the danger of infection to his animals.

The veterinary student who is unfamiliar with the appearance and quality of castrating and other special instruments should refer to any complete veterinary instrument catalogue, which can be readily secured from any reputable dealer.

\section{Restraint}

A thorough knowledge of practical methods of restraint of animals is very necessary in order to become skilled as a castrator. It could not be the intention of any right thinking veterinarian to employ restraint to the exclusion of anesthesia; however, oftentimes a casration operation, skillfully performed on a conscious animal, may inflict less real shock and distress to the subject than complete anesthesia used under average 
conditions. Proper restraint constitutes a very essential part of the operation for successful castration, and this means applies not only to the preparation of large animals but to the smaller ones as well.

Veterinary surgeons are not agreed as to the best method of procedure in the handling of larger animals in many instances, but while their opinions may differ in this, the result sought is the same, so that while one man may confine an animal in some specific way that departs radically from the manner ordinarily employed, he may, nevertheless, be a very practical and successful operator. In the handling of horse and mule colts for castration there are probably many more practitioners who cast the animals in some secure manner than there are who perform the operation with the subject in standing position. Each of the two methods has its advantages and its disadvantages, which may be summarized as follows:

The standing operation is practicable in colts that have attained sufficient size to allow for the work with a certain degree of convenience to the operator, but it is not practical and is difficult to perform in undersized subjects-particularly so in mules, where the testicle is not well developed and the cremaster muscle active in contraction. The standing operation requires less time and exertion for one skilled in its performance, but it is sometinies prolonged because of the inability of the operator and his assistant to properly control the animal, and it occasionally becomes impossible to cope successfully with certain abrormal conditions encountered, thereby necessitating interruption of the work for the purpose of casting and tying the subject so that the task may be completed. Fortunately for both operators and animals, such conditions are rarely encountered. 
It is quite impossible to operate upon the standing animal and execute as nearly perfect a technic with respect to cleanliness as may be done upon the recumbent animal. The average operator would probably not meet with sucesss in the hamelling of other animals than colts that are sufficiently tractable to be readily haltered.

All conditions and emergencies taken into considera-

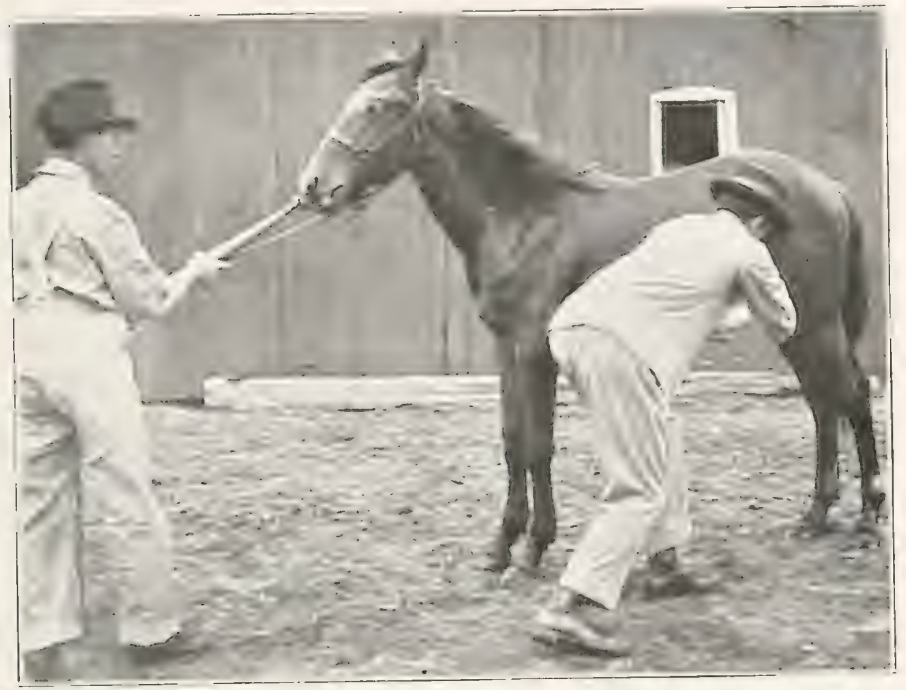

Fig. 5-CASTRATION OF THE COLT IN A STANDING POSITION The cperator is clcse to the subject yet not contacting the animal

tion, it is evident that the performance of castration upon the standing subject would be only successfully

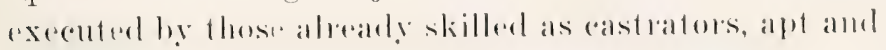
adaptable as horsemen, and sufficiently agile to protect themselves when necessary. The operation is advised only in animals that are normal with respect to the position and development of the testicles; where 
there exists no hernia or other abnormal conditions which might seriously interfere with the work, and in colts having developed sufficiently to mable the operator to thoroughly execute the technic.

The matter and manner of restraint of his subjects is of great importance to the veterinarian, and he should not be wanting in proper judgment and skill to employ the most practical, the safest, and most hu-

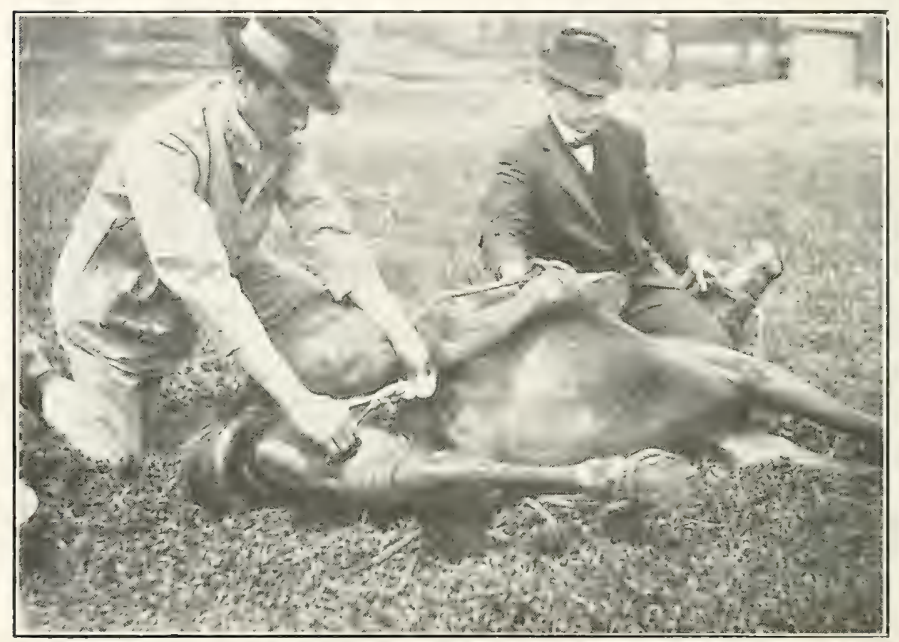

Fig. 6-A PRACTICAL METHOD OF RESTRAINT FOR CASTRATING COLTS

mane means in every instance. Experienced castrators have demonstrated that the wild, untamed colt is handled with the minimum degree of resistance when quickly and securely confined in recumbency, and also that the large, lethargic draft colt is more easily handled in a gentle, leisurely, yet skillful, manner. In the first instance there may be need of a lariat rope and the employment of the old simple method of "hog 
tying," whereas in the second case the subject may be castrated while in the standing position, or he may be gently and quietly cast and confined with some practical harness. In short, it is necessary to use different methods to suit the number of varying cases.

The veterinarian should never disregard the fact that a certain amount of responsibility rests upon him in regard to the employment of untrained assistants, and their likelihood of meeting with accidents in the handling of animals. In the absence of precautionary advice, the volunteer or untrained helper may suffer painful injury, and it therefore behooves the practitioner to warn and so place his clients when they are lending assistance that he - the practitioner-may not be charged with wilful neglect in this matter. It is likewise most important that the animals placed under restraint be handled in an extremely careful manner, to prerent their becoming injured. Such forethoughtful measures will discourage attempts on the part of the client to collect indemnity in case of accidental injury or loss of the patient. 



\section{ANATOMY OF THE STRUCTURES DIRECTLY INVOLVED}

The testicle is a structure that is composed of glandular, vascular, nervous, and fibrous tissues, and its location in the different animals varies somewhat. It is supported more or less closely to the body by means of the cremaster muscle, fibrous integuments of the cord, and by the scrotum. The cremaster muscle has its origin at the posterior portion of the inner abdominal ring, and, according to Sisson, originating from the iliac fascia near the origin of the sartorious. The distal attachment is by means of the tunica vaginalis communis.

The spermatic cord consists of fibro-areolar structure loosely enveloping arteries, veins, nerves, and the vas deferens. The spermatic artery is given off from the aorta, and the spermatic vein furnishes a means of return for the blood. Lymph vessels accompany the vein and empty into the lumbar lymph glands.

The vas deferens, which is also contained within the spermatic cord, is a continuation of the epididymis, separating itself from the vessels located in the anterior. portion of the cord, as it enters the urogenital fold. The nerve supply is derived from the renal and posterior mesenteric plexuses.

The scrotum or pouch containing the testicles is composed of layers derived from the skin and other integument forming the abdominal wall, and from without inward are the skin, dartos, scrotal fascia, 
tunica vaginalis communis, and tunica vaginalis propria. The dartos is derived from the abdominal tunic; the scrotal fascia is contributed by the oblique abdominal muscles; the tunica vaginalis communis is a continuation of the parietal peritoneum; and the tunica vaginalis propria is the mesorchium of the fetus. These coverings are not proper to the testicle, but, strictly speaking, are coverings usually considered as forming the scrotum.

The proper covering of the testicle is the fibrous, inelastic, closely-investing tunica albuginea, which is not directly attached even to the tunica raginalis propria. In the immediate region of the serotum there is to be found in some cases in colts an abnormal development of branches of the external pudic veins forming plexuses. This is common in eryptorchids.

There is much difference in the comparative size of the testicles in the various domestic animals. Bulls, sheep and goats have comparatively large testicles, which are supported in the sub-pubic region in a pendent manner, exposing these glands to injury from ballotment between the thighs or from actual violence in many other ways. The testicles of the boar are comparatively large but closely invested by the scrotum, and situated in the external perineal region in such manner that they are well protected. In the horse the testicles are comparatively smaller than are those of the animals aforementioned, supported rather more closely to the body in the sub-pubic region and ordinarily not subject to injury except from chafing, this occurring more often in light harness horses put at fast work. 


\section{METHODS OF CASTRATION}

In the castration of animals the practicability of any given modus operandi can only be judged according to the convenience of the veterinarian and the lossible difficulties to be encomtered in varying cases. Ablation of the testicle being the essential object of the operation, assuredly, then, it behooves the surgeon to accomplish this result in the most practical manner possible, with the least discomfort and danger to his subject and to himself.

A consideration in the performance of this operation is the danger of hemorrhage, and because of this jossibility being greater in certain animals, the instrument to be used should be selected accordingly. In subjects prone to suffer hemorrhage, the employment of the ecraseur, the emasculator, ligatures, or even the wood clamp, is indicated; but for all practical purposes where hemorrhage is improbable, removal of the tusticles may be safely and immediately accomplished by the use of the knife. The use of the ecraseur or emasculator in the castration of a weanling pig, for instance, is impractical, and is not a favorable choice for the operator. In animals where there exists some possibility of hemorrhage, the knife may be employed in such a manner that the tissues severed are scraped and not keenly divided, and a moderate degree of "unlimited" torsion of the spermatic cord-twisting it round and round-and then dividing the tissues by scraping, lessens the danger of hemorrhage. 
Histologically considered, the tunica intima of arteries is the most delicate layer of the three, and where any sort of manipulation of an artery results in injury to this innermost layer, retraction of the tissue follows. With such retraction and contusion, the lumen of the vessel is materially lessened, and coagulation of blood is hastened. This inner tissue of the arterial wall is the least resistant and will be divided before the outer structures are crushed; therefore any instrument that will effect the division of the tissue surely, and cause sufficient contusion to insure coagulation of arterial blood, will serve for the safe removal of the testicle.

While the term castration only refers to the ablation of the testicle, other means of rendering animals sterile are sometimes resorted to. The secreting power of the testicles may be destroyed and still leave them in situ. These painful methods are employed in countries where the production of castration wounds are inadvisable because of the possibilities of infection resulting in tetanus or other dangerous maladies. The destruction of the secreting power of the organs may be brought about by a subcutaneous torsion of the testicles by digital manipulation-the testicles being placed in a position that causes complete obstruction of the circulation and resulting in aseptic inflammation. and eventual atrophy of the glands.

In animals having a pendent scrotum, the spermatic cord may be erushed subcutaneously between the edges of pieces of wood or other blunt objects, which will ultimately cause atrophy of the testicles and sterility; or a ligature applied above the constricted portion of the scrotum, situated above the testicles, will in about two weeks cause sloughing of the scrotum. But such barbarous methods inflict much suffering on 
the subject, and while they have been necessary in some sections for local reasons, to the scientific and humane mind they should be termed obsolete and unworthy of consideration.

Castration operations may be regarded under two general headings with certain modifications, and are

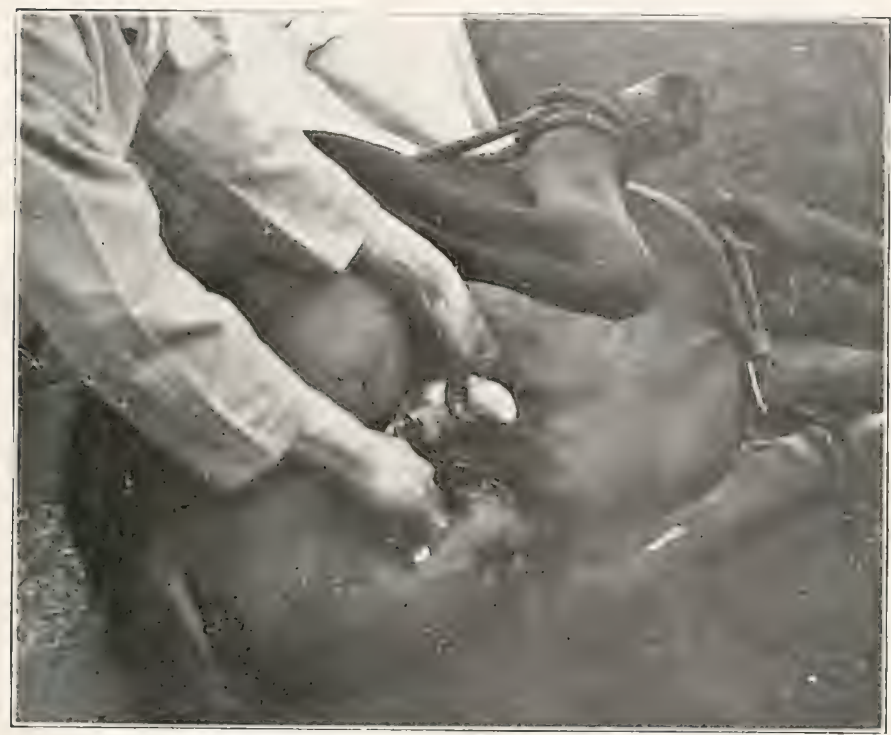

Fig. 7-THE "COVERED OPERATION," SHOWING EMASCULATION OF THE TESTICLE AND ITS INTACT VAGINAL COVERINGS

to be classed as the uncovered operation and the covered operation.

The uncovered operation is the one usually employed and is the more practical in the valous animals when the subjects are in a normal condition. This operation ronsists in the expostre of the testicle proper by means of an incision through the scrotum, such 
incision penetrating the skin, dartos, scrotal fascia, and both layers of the raginal tunic, thereby exposing the testicle within its own adherent covering and subsequent ablation of the gland.

The coverect operation is indicated in cases of scrotal or inguinal hernia and is excented by incising the skin and dartos and by breaking down the scrotal fascia, thus exposing the tunica vaginalis communis, but not perforating it. By careful blunt dissection in the process of severing the attachments of the scrotal fascia, the operator is enabled to cause protrusion of the testicle confined in its own proper covering plus both layers of the vaginal tunic, providing for the application of a clamp, or ligature, en masse, before the actual ablation of the testicle is effecter. 


\section{CASTRATION OF THE HORSE}

\section{Normal Colt}

Since there are more colts castrated and restrained in recumbency by means of some sort of harness, this shall be described as the principal method of restraint. After having cast and securely tied the colt on its left side (for the right-handed operator), an assistant is stationed at its head to prevent the animal doing itself injury. The tail is then either held under the foot of the operator or secured in some practical manner to preclude its being thrown over the surgical area.

\section{Preparation of Subject}

The surgical field should first be cleansed of any dry dust or particles of filth which may have been thrown there during the resisting struggles of the animal. Having at hand, in a clean vessel, about a gallon of suitable antiseptic solution (a one per cent lysol solution, or formalin one-fifth of one per cent), the scrotum is then rinsed off thoroughly.

\section{Operative Procedure}

The castrating knife and emasculator should be in readiness. The lowermost testicle is seized between the thumb and finger of the left hand of the operator, and a bold incision made parallel with the median raphe for a distance sufficient to insure the free drainage of the wound after the operation has been completed. 
T'his incision, skillfully made, reaches through all of the scrotal wall down to the testicle, yet should not penetrate the testicle proper nor injure the gland. Care in this particular not only minimizes the pain of the subject but in the mature animal obviates the otherwise inevitable result of hemorrhage. If done with care, a moderate degree of traction may be exerted upon the testicle to cause relaxation of the cremaster muscle, but undue force used in such cases may result in rupture not only to the attachments of the cremaster muscle, but to the spermatic vessels as well, and this occurring within the abdominal cavity causes hemorrhage into the peritoneal cavity, with fatal results. In some cases the power of contraction of the cremaster muscle is so well developed that it resists the efforts of the operator to draw out the cord, and in such cases it is wise to work slowly, holding the cord for a sufficient length of time until muscular relaxation occurs. The use of quick force is to be avoided, as said before. The emasculator is then applied as close to the scrotum as possible, and the cord and the lower part of the vaginal tunic is severed there: Hemostasis is not aided by the slow closing of the emasculator, and because this deliberation only adds to the pain of the operation, it should also be avoided.

Subsequent to emasculation, the scrotal wound may be enlarged to prevent the retention of any wound secretion or infective disturbances. Another method of providing for the free escape of wound secretion consists in the making of an incision through the scrotal wall beginning at the median portion of the margin, carrying the incision away at a right angle from the median raphe for a distance of about an inch or an inch and a half. 
In castrating the normal equine subject, both the scrotal incisions are made before emasculation is begun. Because of the fact that the hemorrhage from the uppermost incision is likely to obscure the surgical field, in lateral recumbency, it is preferable to remove the lowermost testicle first.

To obviate danger of hydrocele, in the castration of mules, there should be removed with the division of the cord as much of the vaginal tunics as can con-

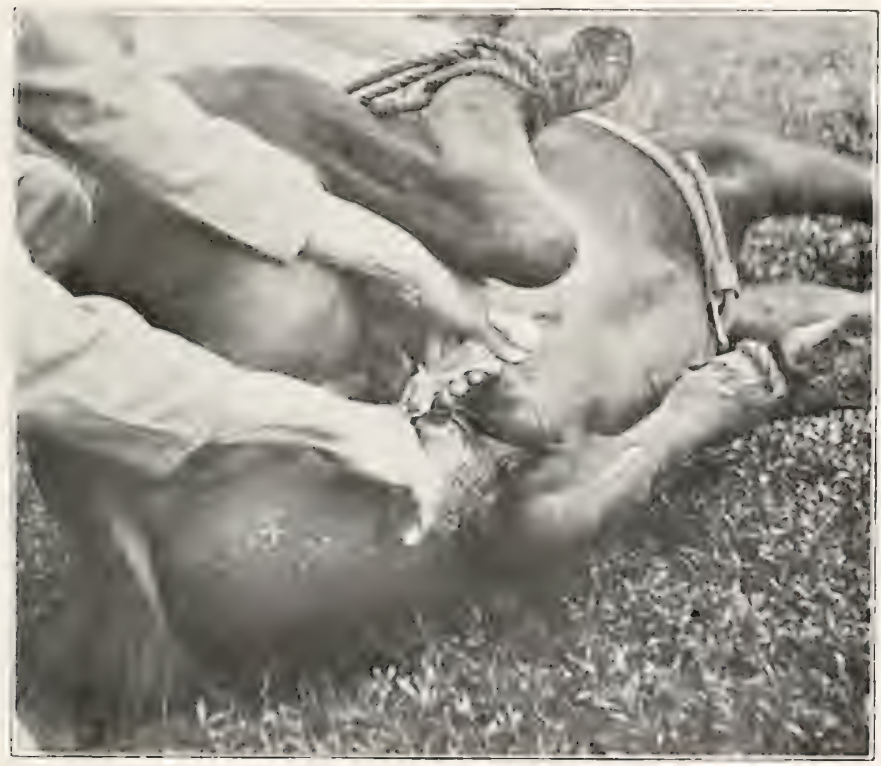

Fig. 8-A MODIFICATION OF THE "COVERED OPERATION" The position of the operator's left hand is such that the testicle is grasped between thumb and index finger, and the vaginal coverings are held in a state of tension, enabling their being grasped within the jaws of the emasculator. This operation is particularly indicated in mules. It practically precludes the occurrence of hydrocele or "water seed."

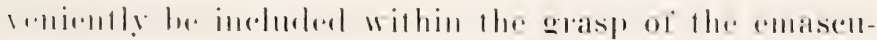
lator. In this way all of the lower portion of the 
tuuica vaginalis is removed, practically precluding the occurrence of the undesirable condition known as hydrocele or "water seed."

\section{After-Care}

Where the operation is executed with due regard to cleanliness with sterile instruments and the hands of the operator uncontaminated, local application of any medicament is unnecessary. It is, however, best to squeeze out any blood that is retained about the emasculated stumps of the spermatic cord. The animal should be provided with clean quarters, allowing freedom to exercise-preferably turned out to pasture and kept away from stables and all barnyard soil. Under average conditions no local attention is necessary and the operation produces but little inconvenience to the subject.

\section{Castration of the Normal Mature Stallion}

For various reasons, occasionally it becomes necessary to castrate the horse after he has fully matured, and in some instances the operation is done in the aged subject. The factors met with in handling such cases that merit special consideration are, the problem of practical restraint, the control of hemorrhage and after-care.

Season.-One should, if possible, avoid castrating the mature stallion during fly-time and in very hot weather. Extremes of temperature have no direct effect upon the outcome of the operation, but these elements in themselves make for discomfort. An unnecessary combination of factors which tend to lower vitality should be avoided if possible. 
Preparation of the Subject.-Food should be withheld for 12 hours before operating, and if the subject can be given suitable exercise (walking or trotting tor a few miles) before being castrated, it will stimulate bowel evacuation and render the subject more tract, able. Sufficient time should be allowed for the subject to cool off if the exertion has caused him to become heated.

Restraint and Anesthesia. - When it is possible, these subjects should be restrained in the standing position since it eliminates the liability to injury from casting. Some young stallions of saddle or light harness breeds are very nervous, and while manageable as they are ordinarily used, are difficult to restrain for standing castration, and the manner in which the subject is to be handled is a problem that the veterinarian needs to decide for himself. In restraining aged animals because of the danger of fractures of bones resulting, it is best to operate with the animal in the standing position.

The rectal administration of from one to two and a half ounces of chloral hydrate dissolved in two or three quarts of tepid water a half hour before operating, will serve to produce sufficient stupefaction to materially benumb sensation and prevent the animal from resisting restraint. One-half grain of atropin combined with two grains of morphin and given subcutaneously about 20 minutes before the rectal administration of an ounce of chloral hydrate, constitutes a synergistic combination that will positively produce a degree of stupefaction which will make possible the safe handling of the most nervous animal. The rectal contents should be manually removed before introducing the solution of choral hydrate. 
Preparation of the Field of Operation.-The scrotum and surrounding parts should be washed with soap and water and finally with a two per cent solution of Liquor Cresolis Compositus.

Technic.-The manner in which the operation is performed does not differ in any way from that done in the colt. The uncovered operation is done and great care should be exercised in making incisions through the testicular covering that are amply large to favor perfect drainage. The scrotal incisions need to be not only long, but situated in the most pendent part of the scrotum to avoid retention of wound secretions after operation.

In "standing castration" most operators prefer to use a knife having a hooked blade, and the incisions into the testicular covering are made parallel with the median raphe, from before backward, and through all covering from the scrotum inward, at one stroke of the knife. With a good sharp knife, an experienced operator can in this manner complete the incision almost painlessly and at the same time make it in a way that perfect drainage of wound secretions will follow.

Any good emasculator will serve to effect sufficient hemostasis for a safe operation, but the animal should be tied up and observed for a few hours after castration. Enforced inactivity for 12 hours after castration, if possible, is desirable. Secondary hemorrhage in the adult is no more likely to occur than in the young colt.

After-Care-CThe recently castrated stallion should be kept on pillar reins when not being exercised, and much less infection and swelling will result. He should be given suitable exercise daily and exertion should be active enough to stimulate complete evacuation of all 
secretions that are retained in the serotum. In the average case, exercise is sufficient to prevent extensive edematous swelling.

Because of the fact that more hemorrhage follows castration of the mature stallion there is retained considerable coagulated blood within the scrotum. This should be removed 24 hours after castration by gently irrigating with a one per cent solution of Liquor Cresolis Compositus if the animal is sufficiently tractable to admit of such handling without restraint other than the twitch and the holding up of a front foo ${ }^{+}$. It the subject is difficult to manage, one may ordinarily trust to evacuation of the contents at ending exercis?

Other complications which may rasult in no wise differ from those met with in colts and are considered fully in the scction on Castration Sequelae.

\section{Castration of Cryptorchid Horses}

Etymologically, cryptorchid means "hidden testicle," and is applicable to any animal in which one or both testicles are located elsewhere than within the scrotum. Therefore it is applicable to cases in which one or both testicles are located within the abdominal cavity or, not having completed their nature descent through the inguinal canal. Usage, however, has restricted the term to animals wherein one or both testicles are contained within the abdominal cavity, not having passed through the inner abdominal ring and entered the inguinal canal.

The term monorchid is applied to animals having but one testicle. In human anatomy and surgery this term has been given a different significance, being used to designate an individual having one testicle in the scrotum and the other in the abdominal cavity. 
For convenience, cryptorchids may be classified as inguinal and abdominal. A varying condition to which attention should be called for surgical purposes is found in those cases where the epididymis has descended into the inguinal canal and the inner abdominal ring has become constricted about its ligament, confining the testicle proper within the abdominal cavity. 'This type of eryptorchid or ridgeling is likely to confuse the operator if he has not previously encomntered such conditions.

Abdominal Cryptorchidy.-Cryptorchidy is more prevalent in some localities than in others. In some sections of the United States, about three or four per cent of all horse colts are cryptorchids, and in other localities a much larger percentage of animals are thus affected. The large number of cases found in certain localities may be ascribed to the fact that cryptorchid stallions are used in the stud. So markedly hereditary is this condition that in many cases 25 per cent or more of the colts sired by such animals are similarly affected.

Most operators have found that where only one testicle is retained, it is usually the left. However, in the experience of a few others in some localities the percentage of animals having the right testicle retained in the abdominal cavity is the greater.

A cryptorchid horse is a very undesirable animal from every standpoint; is usually vicious, unsatisfactory and unsafe to handle in the presence of mares, and in the majority of instances he cannot be turned out with geldings, because of his vicious disposition. The condition is diagnosed readily in most cases by their abnormally increased sexual desire as compared to the gelding or even the normal stallion, even though no other manifestation of the condition be apparent. 
The abnormally retained testicle is usually infertile, degenerated, and may be very small and lack development. In other cases the gland is cystic and-rarely there may be found a large dense teratomatous mass. Where history is absent or unreliable, a careful examination of this subject is necessary in order to definitely diagnose the case.

The conformation is characteristic because of the lack of development of the hind quarters in the adult; a full crest, strong masculine features of the head and absence of serotum, are all indicative of cryptorchidism, but it is necessary to examine further to determine the exact condition, whether one or both testicles are retained and whether it is the right or left. One cannot be guided in this solely by the presence or absence of sears in the scrotal region; neither is the absence of a palpable stump of the spermatic cord positive proof that the testicle has not been removed, for in some cases, where animals are operated while very young, there is so much atrophy of the stump of cord that it is not discernible by digital manipulation. The condition may be diagnosed by rectal palpation but this method is not practical in field work.

Age at Which Operation IMay be Performed.-The best age at which to castrate a eryptorchid is a subject on which operators differ. It is certain that a two or three-year-old colt is more easily castrated than is a yearling. However, the yearling colt that shows no evidence of testicle within the inguinal canal is not likely to manifest any change in this part at a later age and should be castrated if healthy, vigorous and not undersized.

Anatomy.-It is not our purpose in this brief work to elaborate upon the regional anatomy of the struc- 
tures pertaining to the eryptorchid. However, some consideration of the inguinal region is in order. In the true abdominal cryptorchid there is necessarily a complete absence of all evidence of scrotum. The structures at this point assume the appearance of an inverted fumnel, and horses manifesting this condition are known by castrators as "blanks." Since no testicle has descended into the canal, the pudic vessels and nerves are closely invested by areolar tissue, and the entire inguinal region in front of the inguinal ligament is closed. At the site of the inner abdominal ring we should consider the anatomy of these animals under two general classifications-the one wherein there exists a definite area of delicate aponeurotic tissue surrounded by a heavier museular margin, this being a portion of the aponeurotic part of the inner oblique abdominal muscle; the other class of subjects are those wherein at the site of the inner ring there is to be found a broad expanse of very thin aponeurotic tissue with no definite heavy surrounding margin.

In the abdominal cryptorchid, the testicle is floating free in the abdominal cavity, contained within its mesorchial covering anchored by the mesorchium in the sub-lumbar region and further attached by means of the gubernaculum testes - a muscular structure attached to the postero-external part of the upper portion of the inguinal canal. Additional attachment is supplied the floating testicle by means of the vas deferens, which is continued from the testicle within its peritoneal coverings through the plica urogenitalis to the region of the neck of the blaclder. Consequently, in seeking the floating testicle, if the free appendage - the testicle or the epididymis - is not readily located, either the gubernaculum testes situated at the postero- 
external part of the site of the inner abdominal ring or the vas deferens located directly opposite may be sought and the testicle anc cord drawn into the inguinal canal.

Preparation of the Subject.-Unless the cryptorehid horse is mature and the alimentary tract well filled, no preoperative dieting is necéssary. However, as in all other major operations, it is best to withhold food for twenty-four hours when circumstances permit. The matter of gaunting an animal for this operation is one which merits considerable attention in that subjects that are "fully made" and well "ribbed up" or short coupled and carrying considerable fat are not likely to be renclered gaunt by even thirty-six hours' fasting. Such subjects should be put on a light diet of concentrates including a little bran, and in the course of three or four days of such dietetic preparation, the intestinal content will be materially lessened.

Restraint.-There is no operation done by the veterinary surgeon where restraint is a more important feature. The cryptorchid should be cast and very securely tied in a position causing him to keep the hocks well flexed and abducted. This is done with the ordinary casting harmess by having the back strap set well back and by winding the side lines over the gastrocnemii and about the feet in the form of a figure eight. Where the side lines are crossed over the back of the subject completing the tie of the left leg with the right side line and the right leg with the left side line, perfect flexion and abduction may be brought about. If the animal is not securely restrained with the hocks well flexed and the thighs well abducted-unless he is under profound anesthesia, any considerable resistance on his part will serve to cramp the hand of the oper- 
ator by compressing the inguinal region with the lhighs and ahlominal mureles. There is nothing which is likely to cause more difficulty during the process of the operation than incomplete restraint.

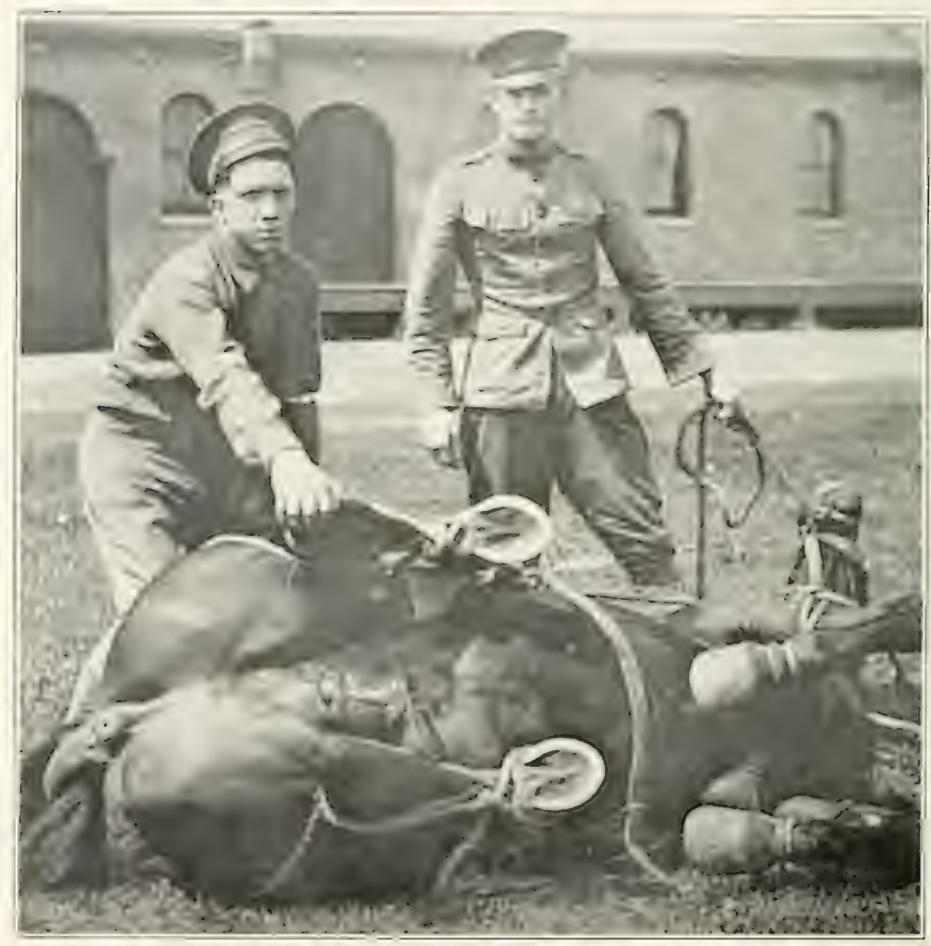

Fig. 9-RESTRAINT FOR CRYPTORCHID CASTRATION Attenticn is called to the manner in which the hind legs are flexed, because immobilization of the hind legs in the position as shown here is a very important part of the procedure of cryptorchid castration. The subject in this particular cut, however, has been restrained for removal of a scirrhus cord.

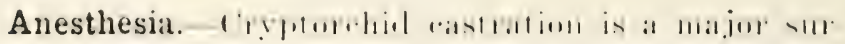
gical operation, yet where it is skillfully performed and where no unusual conditions are encountered ne- 
cessitating delay in its execution, animals manifest very little symptom of shock as a result, even where no anesthesia is used. However, it is well to administer, per rectum, from $1 \frac{1}{2}$ to $2 \frac{1}{2}$ ounces of chloral hydrate dissolved in about two quarts of water twenty minutes before casting the animal. The contents of the rectum should be removed manually by a trained assistant before the solution is introduced in order to get prompt absorption and a good effect.

Surgical Technic.-The field of operation is prepared by first washing thoroughly with soap and water, then drying and painting with tincture of iodin. Care should be taken that loose hairs and particles of dirt or filth are not dropped on the scrotal region.

The animal should be confined in lateral recumbency with the uppermost hock well abducted by an assistant. The skin incision should be made either parallel with the median raphe or over the external inguinal ring and should be of sufficient length to comfortably allow for the introduction of the hand of the operator. Care should be exercised in incising the skin since the external pudic veins if wounded will cause sufficient hemorrhage to obscure the field and inconvenience the operator.

After having incised the skin and dartos, the hand with the fingers in the shape of a cone is inserted into the inguinal canal beginning at the region of the external ring and pushing into the tissues in the direction of the external angle of the ilium, keeping well back against the inguinal ligament, as there is no danger of making this opening too far posterior. This opening of the canal is continued up to the region of the inner ring. Different operators observe different guides in this part of the work. The throbbing of the 
femoral artery in the region of the inner ring is used as a guide by some; others seek the ilio-pectineal eminence. During the process of opening the canal, one should carefully palpate the structures to determine whether or not the testicle or the epididymis has descended into the canal and become lodged therein. Dilatation of the margins of the wound will make possible a visual examination, and the depths of the structures may be further explored by careful palpation. Having made sure that the testicle has not begun its descent, the region of the inner abdominal ring is carefully explored, and here there is need for a modification in the technic in different cases as heretofore classified.

In the subject where the inner abdominal ring is outlined by a muscular margin having for its central portion the aponeurotic part of the inner oblique muscle and where the surrounding area is firm, rather heavy and unyielding-muscular fibres of the transversalis abdominalis and inner oblique muscles, it is well to immediately perforate this thin area at the site of the inner ring with the finger. After having perforated the peritoneum, the finger is immediately turned so as to contact the parietal peritoneum, avoiding the possibility of its becoming invested with floating omentum. If the testicle, epididymis or any portion of the cord is not soon contacted, the operator, by wiping with the finger in the direction of the attachment of the gubernaculum testes, seeks this fold and begins to draw upon said structure, bringing the cord within his grasp, whereupon it may be pulled into the inguinal canal, bringing with it the testicle. Some operators prefer to turn the finger toward the plica uro-genitalis and in a similar manner bring the cord 
within the grasp of the finger, effecting the same result.

In the second class of cases there is found a broad expanse of thin aponemrotic tissue in the region of the inner ring. This expanse of tissue is as large as the palm of the hand in most cases and in such subjects it is well to seek some portion of the testicle, epididymis or cord, recognizing the structures by the sense of touch before perforating the peritoneum. This is usually possible in this class of cases, and the operator by expanding the thumb, index and second finger in the form of the base of a tripod, in this region can make provision for the testicle or epididymis being crowded against and within his grasp by intra-abdominal pressure. Having secured in this manner the testicle or epididymis, the aponeurotic tissues are drawn gently downward, and by careful traction the peritoneum is drawn into the canal for a varying distance in different subjects. In some cases it is possible to draw down this artificially formed processus vaginalis half the way to the external abdominal ring. This having been done, the peritoneum is usually ruptured with the finger and the testicle is readily drawn out and the operation performed with a ninimum degree of contamination of the peritoneal structures. Credit is due Professor W. L. Williams for a good description of this technic.

In the third class of cases, the operator finds in the region of the abdominal ring that the epididymis has descended into the inguinal canal and that the testicle is confined within the peritoneal cavity. In such cases the tail of the epididymis forming an obtuse end is readily recognized. In all cases there is sufficient constriction and organization of the inner abdominal ring 
to prevent the testicle being forcibly drawn down through the ring with any degree of safety. This condition necessitates perforation of the abdominal wall at a point higher than the inner abdominal ring, perforating the peritoneum, securing the testicle and drawing it out of the artificial opening at a point situated supero-posterior to the inner ring. In this manner the epididymis is drawn back into the peritoneal cavity and is drawn out, following the testicle. After having secured the testicle where the cord will permit of its being brought to the surface, it is readily amputated with the emasculator. In some cases the spermatic cord is very short, necessitating the removal of the testicle within the inguinal canal, and this is best accomplished with an ecraseur.

In a class of cases wherein degenerated testicles, cystic, hypertrophic or teratomatous are occasionally encountered, there is need for a departure. from the technic usually employed in other cases. Cystic testicles, if large, may be secured by means of traction on the spermatic cord and the fluid content aspirated with trochar and cannula.

In cases where the retained testicle is hypertrophic, dense and not too large, the operator can with lubricated hand introduced per rectum, crowd the testicle at the same time that traction is exerted on the cord and in this manner effect its removal from the abdominal cavity.

Where the abnormal testicle is of very large size, making it unsafe to attempt removal by the inguinal route, a laparotomy is necessary. This operation should not be done, however, until the inguinal wound has healed.

The technic is executed with the subject under com- 
plete anesthesia. The region of the upper flank is cleansed, shaved and painted with tincture of iodin. An incision through the skin and fascia is made just anterior to the external angle of the ilium, sufficiently large to admit the hand. The muscular structures and peritoneum are perforated by blunt dissection as in cattle-spaying and the testicle likewise is similarly sought. The testicle is brought to the surface of the abdominal wound if possible or if this is not possible ablation of the abnormal structure may be effected within the cavity of the abdomen. The skin and fascial incision is closed with a continuous suture of silk, the wound sealed and no after-care is necessary except to remove the sutures in about a week. Where strict asepsis is observed there is little danger of bad result from this operation.

After ablation of the testicle has been effected by the inguinal route, the cavity may be packed with sterile gauze which is left in position for twenty-four hours and then removed. However, in the majority of cases no packing of any sort is necessary, and animals are exercised regularly as though they had been normal subjects castrated in the usual manner.

Where both testicles are retained within the abdominal cavity, the animal is kept in recumbency, turned over and the operation is repeated, both testicles being removed before the animal is allowed to rise.

\section{After-Care}

After-care in delicate animals consists in keeping them in clean quarters and giving them regular exercise, thus favoring the escape of all wound secretions and minimizing dangers of contamination by pent up discharges with subsequent troublesome infections. 
Young colts that have been rumning on pasture are best turned ont immediately and given freedom to exercise at will. If by accident a large rent is produced in the abdominal wall making protrusion of portions of intestine possible, the inguinal canal should be packed. For this purpose, a liberal packing of cotton wrapped in sterile gauze or muslin should be pushed into the canal as far as the inner ring and confined by means of sutures which join the marginal scrotal wounds. To prevent possible eventration, animals so treated should be confined on pillar reins for about thirty-six hours before the gauze is removed and given exercise in the harness or at the lead and not given liberty to lie down for at least five or six days.

\section{Inguinal Cryptorchids (High Flankers)}

Subjects affected with inguinal cryptorehidy are not as troublesome and undesirable as are abdominal cryptorchids, but they are more so than normal stallions. Cryptorchids are undesirable for breeders even when fertile, therefore castration is always in order.

Restraint.-Animals are cast and tied exactly as are the abdominal cryptorchids; see description on pages 39 and 40 .

Technic.-Because of the fact that in inguinal cryptorchics the cremaster muscle has the power of retracting the testicle and drawing it high up in the canal, this type of eryptorchids is in some instances as difficult to castrate as the true abdominal ridgeling. The technic for handling these cases is executed in the same manner as is done in the castration of the abdominal cryptorchid up to the point of perforating the abdominal wall. The testicle is readily located within its vaginal covering in the canal, and the tunics are pref- 
erably incised with the hooked blade castrating knifo. As soon as the small incision is made into and through the vaginal tunies, some portion of the testicle may be squeezed out through the opening, and amputation of the gland is then readily accomplished. The small opening thus made into the vaginal tunics is easily enlarged after the testicle has been amputated, which is necessary.

After-Care--These cases require no more after-care than is given to the "straight" colt at the time of castration, and the type calls for no special consideration except for the purpose of classifying them as a distinct and separate class of cryptorchids. In these cases the testicle has descended into the canal, the processus vaginalis has been pushed downward and the vaginal tunies formed in such manner as to make them differ from the true abdominal ridgeling. In such abnormal cases of course, no scrotal pouch has formed, but in most instances the testicle is readily felt by palpation of the inguinal region. There are occasional cases, however, where it is impossible to locate the testicle in this manner.

\section{Herniæ}

To be considered under this heading are herniæ, inguinal and scrotal, of foals-a condition due to a loose and lax state of the inner abdominal ring permitting the descent into the inguinal canal of a loop of intestine, which may descend as far as the scrotum. In the typical case of inguinal and scrotal hernixe as seen in foals the loop of intestine is confined within the tunica raginalis communis and on the outside of the tunica vaginalis propria. Strictly speaking, it is a condition wherein the loop of intestine has taken its way along- 
side the testicle and inner vaginal tunic, and the testicle only is contained within its mesorchial coveringthe tunica vaginalis propria. This is most common in foals at or soon after birth, and in the majority of cases causes no particular inconvenience; they are not likely to become strangulated, and in most subjects, spontaneous recovery is the result before the colt reaches the age of six months. As a general rule, operation for the relief of the condition in foals of a few weeks of age is quite unnecessary, as complete recovery so generally follows in the course of sixty days. It is well, however, to inform the client of the possibility of hernia at the time of castration, even though the colt is not altered until he is a year old and recovery has apparently existed for a few months.

Where it is thought necessary to operate to correct the condition, the covered operation for castration is indicated and should be performed as described in the technic of this operation on page 28.

\section{Sequelæ}

Accidents from Restraint.-In the handling of animals for castration, particularly where they are cast and tied, even with the employment of great care and skill, injuries such as serious fractures, contusions, strains and bruises may sometimes occur through the resisting struggles of the subject. Fracture of some part of the vertebral column is a fatal accident that is especially liable to occur where aged animals are cast, or where the subject is over-rebellious against confinement. Symptoms of this injury differ, depending upon the site of the fracture. In the majority of instances, such fractures occur in the dorsal region and a paraplegia results. The animal remains prostrate, unable 
to raise the hind parts or regain its feet. If a thorough "xamination shows positively that such a break exists, the case should be pronounced hopeless and the subject destroyed at once.

Fractures of tuberosities or of long bones may happen likewise, and are to be treated as fractures resulting from other causes; that is, if it is the kind likeiy to yield to treatment. The animal is properly confined in slings and partial or complete immobilization effected according to the best methods usually employed.

Animals resisting confinement sometimes suffer from strains, rope burns, or contusions. While such conditions are not common, where subjects are carefully handled, the client should be informed of the remote possibility so that the veterinarian may not be held responsible for the occurrence of such accidents.

Occasionally if an animal is kept confined for an undue length of time in recumbency, atrophy of the longissimus dorsi muscles oceurs within ten days or two weeks after the animal has been so confined. Such cases are treated along the same general lines as atrophies resulting from other causes, and prompt and complete recovery usually follows.

Hemorrhage.-Hemorrhage following castration happens more frequently in some animals than in others, but for this purpose they may be considered in two classes,-primary hemorrhage and secondary hemorrhage. Primary hemorrhage is seldom of any serious consequence except in cases where faulty instruments are employed in foals, not effecting complete maceration of the cord and causing spermatic hemorrhage. These cases are readily recognized, as the blood from the spermatic artery spurts with each pulsation and 
requires immediate treatment. Because of the fact that retraction of the cord takes place to a marked degree within the vaginal sheath containing it, it is not easy to ligature the cord after it has been closely amputated. Having at hand two pairs of hemostatic forceps, the operator may seize the end of the cord with one forcep, drawing out the tissues as far as possible, and then by seizing the cord again with the other forcep, the bleeding stump is brought to view. After securely clamping the forceps over this stump, a ligature may be applied; a good stout needle with silk thread is passed through the cord above the forcep and the ligature is fastened tightly after having been wrapped around the stump. No further treatment is necrssary although it is best to remove the ligature in about ten days.

In some cases, because of the cramped position of the animal castrated while recumbent, there occurs some little venous hemorrhage; this, as a rule, however, subsides as soon as the animal regains its feet. Should this condition persist to a great degree, the scrotum may be packed with sterile gauze or muslin and the packing confined in situ by means of scrotal sutures, to be removed in twenty-four hours. As a rule primary hemorrhage from castration properly performed, is of no consequence, and spontaneous cessation of the hemorrhage is the rule, within the course of a few minutes, therefore these cases should not alarm the operator.

Secondary hemorrhage from this operation is a condition which is probably due to a state wherein the blood does not normally coagulate,-a condition found perhaps more often in the spring of the year in animals that are not thrifty. Such hemorrhage is not 
noticeable for several hours after the operation has been performed, but if within twelve to twenty-four hours after a colt has been castrated, a steady loss of blood from the spermatic vessel is evidenced, the case should receive prompt and drastic attention, as these hemorrhages may continue for a few hours, yet they have been known to persist for days, rendering the animal anemic and weak, and eausing death in some instances. If much blood has been lost, the animal should be cast and the stump of the cord securely ligatured as described for primary hemorituge.

Shock.-In some eases the attendant fear and unnatural interference of a surgical operation bring about a distraught condition of the nervous system, known as surgical shock, this state being characterized by manifestations of pain, muscular tremors, labored breathing, more or less sweating and acceleration of the pulse, which in the later stage becomes somewhat feeble. Animals so affected exhibit these symptoms to a greater or less degree, and the result may be either a slight or sarious disturbance of bodily functions causing discomfort or it may result in death according to the organism of the subject.

Colic.-This disturbance is sometimes manifested after the castration operation. It is more likely to affect animals of a nervous temperament, and is the consequence of the excitement and resistance incident to being restrained. The symptoms and treatment of such cases do not differ from those of colic produced by other causes. It is well to take the anticipative measure of withholding food for at least twelve hours before operating on these highly strung, nervous animals, as colic may be attended by fermentation and serious trouble follow. 
Hernia.--In some rare instances where animals resist confinement very violently, and where there exists a very loose and large inguinal ring, a loop of the intestine may be pushed out through the inguinal canal, and hernia or even eventration result. In these cases, the condition demands prompt handling; the protruding intestine should be supported by a sling of canvas or other suitable fabric, the subject confined in dorsal recumbency, and the hernia reduced. Reduction by taxis is possible with the subject under complete anesthesia. The cavity should be carefully packed with cotton wrapped in sterile gauze and this packing confined by strong sutures which join the edgas of the scrotal incision. If this can be accomplished before damage is done the protruding viscera, there is some hope of recovery, but the animal should be kept quiet and in the standing position for several days. The subject should be only moderately exercised and not given freedom for two or three weeks.

\section{Swelling of the Scrotal Region and Scrotal Ab-} scess.-Swelling of the scrotum and sheath following this operation is not uncommon and in many instances is not to be ascribed to faulty technic nor lack of proper after-care. When vitality is at low ebb in colts that have been wintered badly and castrated in the early spring, the circulation is enfeebled and they are quite prone to exhibit this condition after the operation. In some instances the retention of large quantities of smegma within the sheath causes the external prepuce to become greatly swollen, this swelling later extending in all directions and a marked edematous condition of the lower abdominal walls may continue for a week or two. In other cases, because of slight swelling which follows the operation, coaptation of 
the marginal wounds of the scrotum takes place and the retained coagulated blood subsequently becomes infected and is naturally followed by considerable swelling. Exercise tends in all cases to minimize postoperative swelling. In the case of the enfeebled animal manifesting much swelling, it is advisable to administer stimulants and scarification of the pendent edematous swollen parts should be done, and where the swelling involves the scrotum proper, the wounds should be reopened, this being readily done with the thumb and index finger. A layman may be instructed to do this with safety, if he is cautioned to introduce the previously cleansed fingers into the wounds, and by means of a bold thrust tear asunder the newly formed adhesions, thus permitting the escape of the pent-up secretions and coagulated blood. Following such manipulation, the subject should be exercised in moderation even though force must be used to make it do so. Nutritive and laxative diet and good hygienic care are necessary. Subjects so affected are best kept at pasture and away from lots and stables.

Scrotal Fistula.- Where the draining of a scrotal abscess is neglected, the condition results in invasion of the tissue juxtaposed. Fistulous tracts are usually found coursing along the sides of the sheath parallel with the median raphe. Where these conditions are neglected, chronic inflammation results with hypertrophy and the formation of considerable cicatricial tissue and permanent enlargement of the sheath. Such cases should be treated surgically by making suitable drainages and removing with the curette or other apluopriate instrument, all detritus, and injecting the parts with tincture of iodin. After-care consists in 
allowing the animal sufficient exercise to prevent too early closure of drainage openings.

Post-Operative Peritonitis.-This condition is a seuruel of the generalization of local infection and is nore likely to oceur in depleted animals that have been improperly castrated or in animals that have been infected at the time of castration through the use of septic instruments or careless manipulations. Likewise the transmission of streptococcic organisms and their introduction while castrating, are very likely to result in fatal peritonitis; however, peritonitis thus developed is not always fatal. It is manifested by symptoms of lethargy, inappetence, stiffness, rise in temperature of from two to five degrees above normal, acceleration of the circulation and a tucked up) appearance at the flank. The subjects are not inclined to move about much, but remain standing generally, becoming restless in the later stages, and lying down, rolling about and getting up again by turns. Locally there is found issuing from the inguinal region, a serosanious fluid, and animals exhibiting this affection should be given prompt local treatment to establish drainage. Laxatives, together with stimulants, should be administered, and the appetite tempted with any good, wholesome food.

Scirrhus Cord.-This enlargement is developed by infection involving the spermatic cord either because of its becoming impinged between the scrotal wound margins and remaining thus exposed for a sufficient length of time to allow contamination, or it may be a sequel of scrotal abscess. In some cases it is said to be caused by botrymycotic invasion. The condition is essentially chronic and is characterized by an indurated necrotic enlargement of the spermatic cord in- 
rolving the tissues adjacent. Animals so afflicted may manifest little uneasiness or discomfort except at certain periods when the affected parts become greatly swollen, causing local soreness, pain, and some lameness. The necrotic process results in the formation of more or less pus which eventually makes its own outlet. The secretions are discharged and in the course of a few weeks the wound closes and the process recurs again in the same course of time. This slowiy destructive affection may cause the tissues involved to assume proportions quite large, and is painful and inconvenient for the animal. The condition is distinguished from hydrocele and hernia by its dense and hypertrophic character which involves the surrounding tissue as well.

Treatment. - The subject is cast and confined as for cryptorchid eastration, and a rectal administration of $11 / 2$ or 2 ounces of chioral hydrate dissolved in a quar: of tepid water twenty minutes before operating, is suggested. The surgical field is cleansed as for castration; the cicatricial pendent portion of the scrotum is secured with vulsellum forceps and an elliptical incision is then made including the tissues thus grasped. By dissecting around the pear-shaped mass, the necrotic structures ara separated from the tissues adherent, taking care not to include too much healthy tissue. Thus the mass is earefully separated up to a point where the cord is in a healthy state, and ampritation of the mass with the ecraseur is effected. In the average case, it is found that the cord is diseased rrithin the inguinal canal only and it is exceedingly rare that the involvement extends as high as the inner abdominal ring. However, there are recorded cases where the cord has been affected into the abdominal 
cavity and such cases are, of course, inoperable, since it is not ordinarily reasonable to attempt to amputate the cord at a point higher than the inner abdomina? ring.

Hemorrhage is controlled during the operation by means of forceps if any very large vessels are encountered. In this operation, however, there is generally much oozing of blood and the dissection is usually done rapidly, consuming as little time as possible. The cavity is snugly packed with sterile gauze to be held in position by suturing, and this will control the possibility of hemorrhage during the twenty-four hours it is to be left in the cavity.

After-Care--After attention consists in allowing moderate exercise and applying locally if conditions require, a dry dressing powder by means of an insufflator. In botryomycotic infections, potassium iodid is of value.

Hydrocele.-Hydrocele, commonly known as "water" seed," is an affection frequently found in males where э. portion of the tunica vaginalis becomes involved in such a manner that a cyst-like enlargement results. It is more often seen in mules. The operator should remember that this condition is generally the sequel of an imperfectly performed castration where the tunica vaginalis has not been freely opened, or where the lowermost portion of the tunic was not amputated at the same time the cord was divided.

Symptoms.-Symptoms of hydrocele are the existence of a fluctuating enlargement occupying the position of the testicle,-- this to be distinguished from hernia in that it is irreducible and somewhat more dense, -and also there is a marked constriction and presence of dense tissues at the point of attachment at the 
stump of the cord which is detected by palpation and which is not found in hernia.

Treatment.-Subjects so affected should be cast and tied and the area of operation prepared as for castration. An elliptical incision is then made in the scrotum, to include the castration scar. By careful dissection the cyst-like enlargement is separated from the tissues without eutting through its wall, up to a point where it is attached to the cord, and ablation is then effected by means of the emasculator or ecraseur. This operation is a very simple one if the wall of the cyst is not perforated, and when this enlargement has been removed completely, with the amputation of the cord at or above the site of adhesion of the vaginal tunies, recurrence of this affection is not possible. 



\section{CASTRATION OF THE BOS}

The scrotum of the bull is located more anteriorly than is that of the horse, and is more pendent, having the long axis of the testicles vertically situated. The cremaster muscle is large and well developed. The spermatic cord is very long, and after the attachment of the cremaster mucle has been severed, the cord will allow of the testicle being drawn well out from the scrotum. In no other conseruential way does the anatomy of the structures directly concerned in castration of the bull differ from that of the horse.

Males of the bovine species should be castrated at a very early age to obtain the best results, but since this is not always convenient, castration is often deferred until the animals reach the age of six or eight months. Therefore, subjects under this heading shall be considered with respect to their varying ages. Animals four months of age or older are preferably handled in the standing position as it requires less time in that manner and is more convenient and practical than when the subject is confined in recumbency.

Castration of Young Calves.- When possible, the male calves should be castrated while very young,as they are easily handled even when only two or three days old, are but slightly inconvenienced and apparently suffer no shock from the operation. These subjects should be restrained in recumbency, for, as a rule, they are not particularly resistive and may be easily held by an assistant. In most young subjects the scrotum is covered with hair and the testicles are 


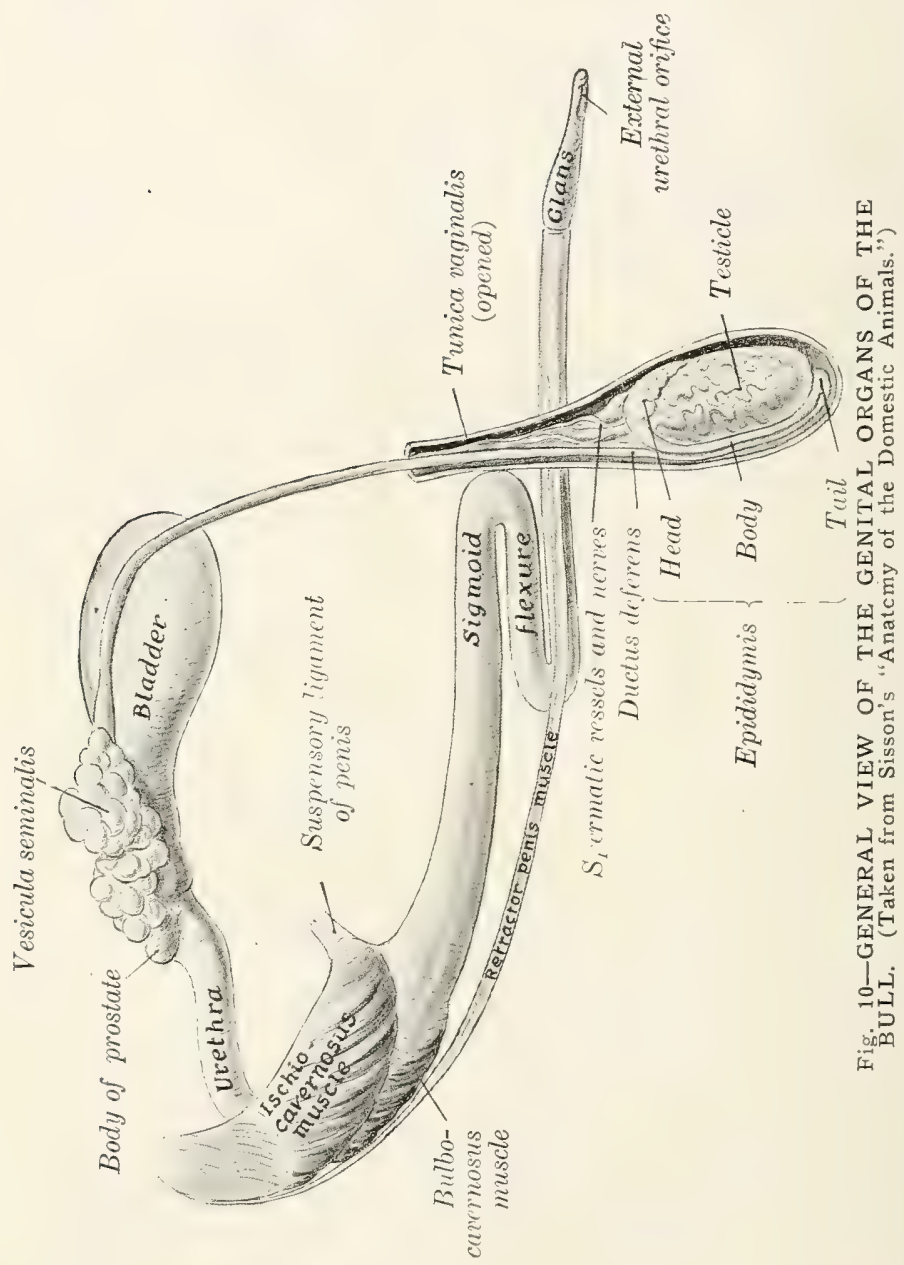


so very small and undeveloped that it is somewhat difficult to secure the testicle for the purpose of incising the serotum. To follow a very practical and conrenient method of castration, have in readiness an operating knife with a pointed blade, then by seizing the fundus of the scrotum with the thumb and finger, the instrument may be thrust through the scrotum at

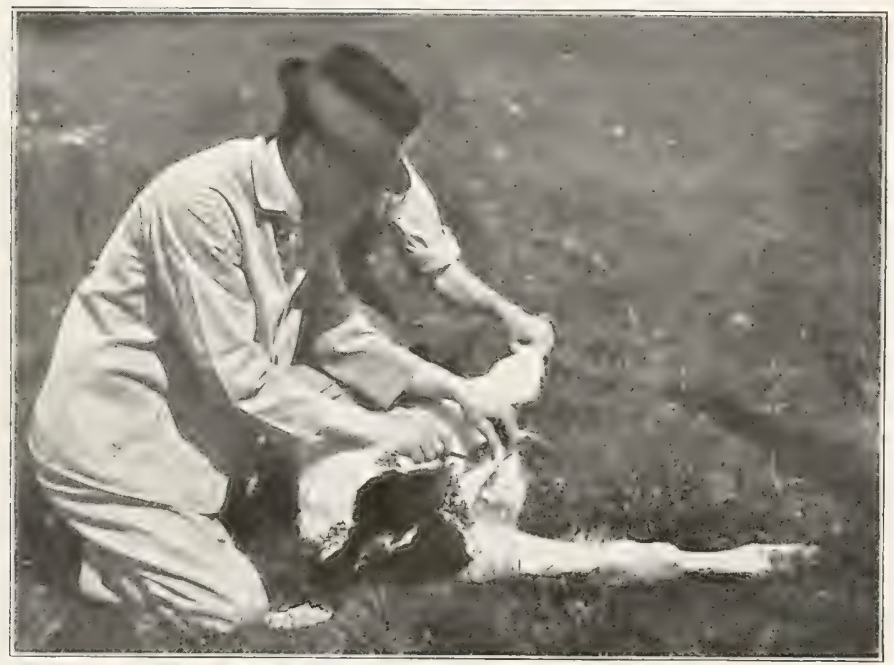

Fig. 11-CASTRATING THE YOUNG CALF

Showing manner in which the scrotal incision is made; also a practical method of restraint.

right angles with the median raphe. The location of this puncture is sufficiently remote from the bottom of the scrotum to insure an amply large and free opening of both sicles of the pouch by carrying the incision through the tissues and simultaneously opening both halves of the scrotum. An incision is then made in the vaginal tunies, this being done by seizing the testicles which remain encapsulated within their serous 
coverings, and the operation is completed by exerting a moderate degree of traction on the exposed testicle, and dividing the cord by scraping with the knife. With the employment of this technic the operation is quickly and almost painlessly accomplished, hemorrhage is avoided, perfect drainage is provided for and

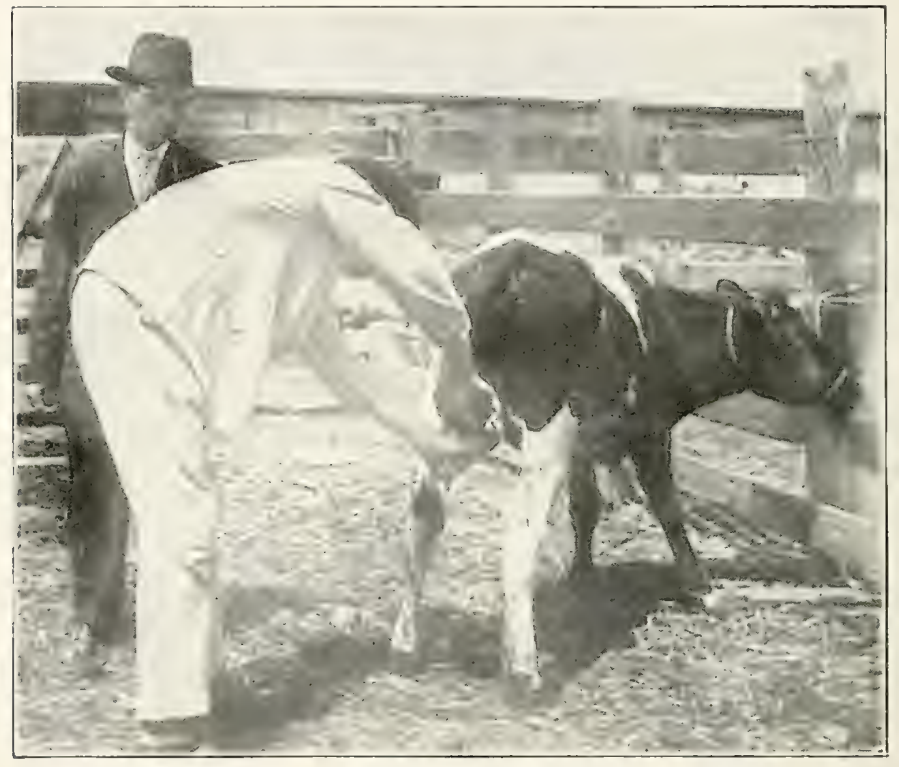

Fig. 12-RESTRAINT OF CAIF IN STANDING POSITION FOR The subject is securely tied by means of a lariat or halter, and an assistant further restrains it by holding the tail. The operator is shown in the act of removing the end of the scrotum by means of a transverse incision.

the scrotal pouch is left nearly intact. All details being carefully observed, the subject requires no aftereare.

Castration of Calves.- Inder this heading, animals of two months of age or older shall be taken into con- 
sideration. Such subjects when healthy and vigorous are more casily castrated in the standing position, being confined in a stanchion and held against the side of the partition by an assistant, or, after catching the animal by the head with a lariat rope, snubbing it to a post, and having the assistant grasp the subject by the tail, holding the hind parts firmly against a fence or partition.

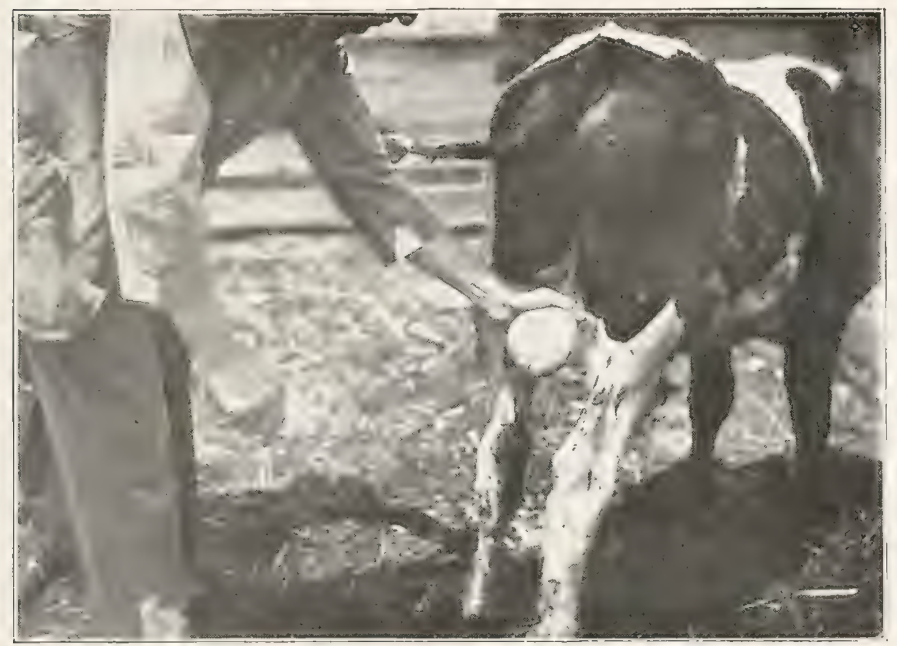

Fig. 13-SHOWING POSITION OF OPERATOR, ALSO LINES OF INCISION PARALLEL TO THE MEDIAN RAPHE OF THE SCROTUM INDICATING LOCATION OF INCISIONS

Unless the scrotal region is badly soiled, no particular cleansing of the parts is necessary. The operator takes his position behind the animal, seizing the scrotum in such manner that a vertical incision may be made on the lateral sides of the scrotum, exposing the testicles with one stroke of the knife. All tissues should be divided from without, within,-- that is, from 
the outside inwardly,--including the raginal tunies as indicated in the uncovered operation. The attachment of the cremaster muscle is then severed, and with moderate traction upon the cord, the testicle is drawn downward as much as the structures will permit without danger of fibrillary laceration. The cord may readily be amputated by means of an emasculator.

Some operators prefer to remove the fundus of the scrotum and in this manner expose both halves of the pouch; this procedure is followed by grasping the foremost portion of the skin and dartos whereupon the subject, by means of contraction of the cremaster muscle, usually elevates the testicle to such a degree that as much as one-third of the scrotal pouch may be divided by one bold incision directed at right angles with the median raphe. This method provides for clear drainage, but because of the incidental sacrifice of a large porcion of the scrotal pouch, steers are deprived of what is termed the "purse", or "cod,"-an undesirable condition in the fatted animal, according to many fanciers. For the completion of this method of castration, the operator follows the procedure that has just been outlined in the preceding paragraphs under this same heading.

After-Care.-The only after-attention to be considered is the provision of clean quarters for the subject, unless the operation is performed at a time when flies are prevalent, when trouble is likely to arise from that source. The animals are best turned out to pasture if the weather is not cold.

Castration of Mature Bulls.-Mature subjects of this species are prone to suffer considerable hemorrhage following any ordinary operation for castration unless ligatures are employed. These animals are handled 
best in the standing position, confined in a stanchion or simply tied with a halter, and as a rule, no special precaution is taken for the safety of the operator. It is possible to employ a rope which is passed around the body of the animal in the region of the flanks, and drawn quite snugly for the purpose of subduing the patient to some extent should it be necessary; in that it prevents the animal from kicking, it is a wise pre-

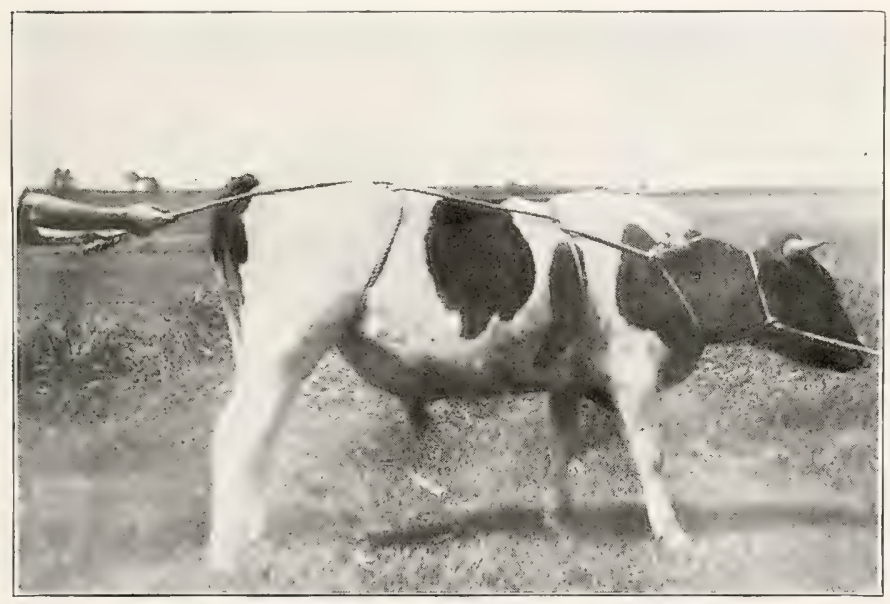

Fig. 14-RUEFF'S METHOD OF CASTING

This mode of casting is very practicable with most subjects that are not too large and strong.

cautionary measure. In the case of vicious subjects, they may be cast with English hopples to enable the operator to do his work conveniently and without danger.

When bulls are confined in the standing position, the surgeon takes his place behind the animal, and scrotal incisions are made as described in the operative technic for younger animals. Likewise the 
lower attachment of the cremaster muscle is severed and the testicle drawn downward by means of moderate traction. The exercising of "unlimited" torsion by rotating the testicle on its long axis fifteen or twenty revolutions before applying the emasculator, will serve to further prevent the possibility of serious hemorrhage. Some operators prefer savering the cord by employing traction and "unlimited" torsion until the structures are almost completely divided, cutting only the more dense remaining structures, and in this manner preventing severe hemorrhage. It is also possible to divide the cord by exercising "limited" torsion, employing for the purpose a heavy compression forcep which is clamped upon the spermatic cord as close to the inguinal canal as it can be placed. By means of this forcep, torsion is restricted to such point on the cord as is confined within the grasp of the forcep, and by twisting the testicle and rotating the cord on its long axis, the structures are simply ruptured by twisting,- the forcep serving as a restricting agent, thereby limiting the extent of torsion.

After-Care-Immediately after being castrated, the subject should be kept in clean quarters and allowed room for sufficient exercise to insure the escape of wound secretions and to minimize post-operative swelling. In fly-time it becomes necessary to apply certain repellent agents such as carbolized oleum picis. To promote the welfare of the subject it should be given a laxative diet.

\section{Cryptorchid Bulls}

Cryptorchid bulls are either interstitial or abdominal,- the latter being those cases in which the testicle may be found floating within the abdominal cavity. 
Interstitial cryptorchids are those where the testicle is concealed in the subcuticular abdominal structures lateral to the external prepuce. To establish elassification wherever possible, it is well in all cases of cryptorchidy to carefully examine the region of the animal's flank for the likely location of the testicle in this vicinity.

\section{Preoperative Preparation of the Subject.-Food} should be withheld for a period of twenty-four hours, and administration of a pound of magnesium sulphate twenty-four hours before operating, is in order.

Restraint.-For this operation animals are preferably confined in the standing position, being restrained in a suitable stanchion or crowded alongside a wall or partition, by means of a stout pole. Thirty minutes before operating, the subject should be given a drench of from one to two ounces of chloral hydrate dissolved in one or two quarts of tepid water.

Technic.-The flank region anterior to the external iliac spine should be freed of all hair by clipping, and the field properly cleansed with a mild antiseptic solution. An incision is then made as for spaying, between the anterior angle of the ilium and the last rib, - this incision being directed downward through the skin and fascia,-and by blunt dissection the abdominal muscles may be separated, the operator forcing his hand through the abdominal wall into the peritoneal cavity. Exploration is then made of the pelvic portion of the cavity, as in spaying, and as a convenient guide, it is well to note the shaft of the ilium. The operator then seizes the urogenital fold, and the cord is readily and quickly traced from this point, the testicle is brought to the surface and removed with the emasculator or spaying scissors. The skin and fascia 
wound is closed by means of a continuous suture and the wound margins smeared with pine tar. No aftercare is necessary but if convenient, it is well to remove the sutures in about a week.

Interstitial Cryptorchidy.--In cases of this type the testicle is often found concealed in the lower abdominal wall, usually covered by the skin and fascia, and located in the region of the flank or alongside the sheath. The testicle may readily be recognized by its firm contour, and is secured by incising the skin and fascia directly overlying it, and thus exposed, the testicle is removed with the emasculator. The skin incision is not necessarily sutured as the usual location of the testicle in these cases is such that a very small opening will enable the operator to secure and remove it, and the position of the wound provides for good drainage. No after-care is customary.

\section{Sequelæ}

In the castration of adult or aged bulls, resultant post-operative hemorrhage is a condition frequently encountered, and because of the sometimas serious consequences, it becomes urgent that the veterinarian observe well and follow the preventive measures provided for in the successful performance of this operation on mature animals. Where the operator employs a good emasculator or ecraseur and takes reasonable precaution against hemorrhage, fatality is not likely to result from the operation. Where hemorrhage exists in a degree not evidently death-producing, the internal administration of atropin in a full physiological dose will prove very beneficial. The confinement of the subject in inactivity in a tie stall for from 24 to 48 hours will also faror spontaneous hemostasis, and 
the additional nse of hemostatic agents such as exsiccated alum, iron subsulphate, or air slaked lime, applied locally by means of an insufflator, is of great aid. In cases of profuse hemorrhage and where the life of the subject is endangered, he should be cast, "hog tied," and the scrotum packed with gauze held in position by means of scrotal sutures,-this packing to be carefully removed in 24 hours. It is most important that animals so affected be kept in clean quarter's and without privilege of exertion for at least 24 hours, and in the days immediately following this treatment they should be allowed only a limited amount of exercise.

In these cases, the scrotal wounds must be given careful attention, subsequently, to observe and prevent the closing of the drainage opening, which might result in serious infection. In about 48 hours, if the coagulation of blood has rendered the continuance of hemorrhage improbable, an irrigation of the wound with a one per cent solution of Liquor Cresolis Compositus will be beneficial.

Following castration of calves, venous hemorrhage is of frequent occurrence, but in these cases the loss of blood is not of sufficient amount to cause serious disturbance, and no attention is necessary other than to restrict exercise and keep the subject under observation lest the hemorrhage continue to a degree demanding treatment. Remedial efforts should be followed in these subjects the same as described for the bull.

Internal Hemorrhage.-Internal hemorrhage may result where undue traction has been exerted upon the cord, causing rupture of the spermatic vessels at a point within the abdominal cavity, either with or 
without obstruction of the inferior inguinal region. This accident is characterized by the symptoms which attend all cases of internal hemorrhage, such as an acceleration of the heart, weak pulse, unsteady gait, paleness of visible mucosæ, muscular tremors, and finally labored breathing, collapse and death of the subject. Treatment generally proves futile in cases where profuse hemorrhage exists, but in some instances, such agents as atropin, which decrease vascular constriction, may be of service; the intravenous injection of normal saline solution in moderate quantities, is also beneficial in some cases. Animals so affected should be kept quiet and unnecessary disturbance avoided.

Infection of the Wound.- While bovine subjects seemingly are very resistant to ordinary infection, yet post-operative infections do occasionally occur, due in part to the inertia following the shock of the operation of castration. This inactivity enhances post-operative swelling and edema, which make for the retention of wound secretions and coagulated blood. In the course of two or three days under these adverse conditions, infection takes place and the subject manifests evidence of intoxication from the absorption of products of bacterial activity thus incited.

Where bulls are castrated in cold weather under unfavorable conditions, and not provided with proper shelter, this element of cold combined with the animal's marked disinclination to exercise after the operation, does not conduce to increase the powers of resistance, but favors serious infectious disturbances, and losses on this account oceur.

Symptoms. - Symptoms of post-operative infection consist in the general inclination of the animal to seek 
quiet and isolation,- the refusal to eat only certain things, if any, - a painful local swelling and a noticeable tendency on the part of the subject not to move about. Where the infection is serious or becoming generalized, there is fever, constipation, disturbed circulation, increased thirst, the frequent changing of position from that of standing to recumbency, and death may follow within the course of three or four days.

Treatment.-If taken early before any material generalization of the infection has taken place, the confining of the subject in recumbency and the free opening of the scrotal wounds and irrigation of them with a one per cent solution of Liquor Cresolis Compositus, is helpful. A purgative dose of magnesium sulphate will aid in correcting the condition and the daily irrigation of the serotum with the solution just mentioned is generally all the local treatment that is necessary for recovery. The treatment is to be continued for several days until the animal has improved and the wound assumes a more nearly healthy condition.

Where the subject has been neglected until there is evidence of considerable generalization of the infection attended by fever, inappetence and soreness, with disinclination to move, the prognosis is not, as a rule, favorable. Such cases should promptly be purged, and if possible, supported with stimulants such as strychnin, alcohol or echinacea-angustifolia. The scrotal wounds should be freely opened and curetted, and this should be followed by frequent irrigation of the wounds with suitable antiseptics. The subject should receive the best care and made as nearly comfortable as possible.

Contamination by Flies.-The larvæ of Lucilia ma- 
cellaria may do considerable damage by way of contamination of the castration wounds. When this condition prevails, the animals should be confined suitably, the wounds curetted, and immediately irrigated with chloroform or aqua ammonia. This procedure includes the regular irrigation with a suitable antiseptic solution, following, and further prophylactic treatment consists in the local application in proper suspension, of agents that are repellent to the fly, most of these mixtures containing tar or napthalene, and being suitable for this purpose. 


\section{CASTRATION OF SHEEP}

Lambs are generally castrated at about two months of age, and while these animals are not as hardy nor as resistant to surgical interference, as are some animal subjects, under the proper conditions mortality from castration is usually very low. Since the anatomy directly concerned in the castration of sheep is similar to that of the bull, no description of these structures need be given here.

Restraint.-Subjects should either be confined in lateral recumbency and held by an assistant as though hog tied, or they may be seated in an upright position and thus supported between the knees of an assistant who may secure within his grasp a front and hind leg on each side of the animal. In this attitude, the dorsum of the subject is held against the body of the aid, and the scrotal region is thus placed in an accessible position for the operator.

Technic.-Where the element of time is not to hinder, preoperative clipping of the hair or wool over the scrotum should be done. This is followed by scrubbing the parts with a one per cent solution of lysol or Liquor Cresolis Compositus, and the operation is completed exactly as indicated in the section on castration of the bull.

After-Care--Postoperative attention consists in the provision of sanitary and comfortable quarters, and since this operation should not be performed during fly-time, no especial after-care is ordinarily needed. 


\section{Sequelæ}

Owing to the difficulty of securing the testicle in lambs, there is considerably more manipulation of the parts generally necessary at castration, than there is for the same operation in calves and pigs, and this, of course, offers greater possibility of infection. Furthermore, the wool about the scrotum being longer, that, also, is a more frequent source of contamination in lambs.

However, fatalities from infection are relatively low in sheep except in the event of tetanus. Some corrals wherein sheep are kept seem to become seeded with an unusual amount of tetanus infection, and the result is that about 25 per cent of the lambs castrated in herds having access to such corrals, die of tetanus. Even the utmost surgical precaution or purchasable preventives that the average owner will countenance, will not serve to curb this virulent germ once it gains headway in a herd. The recurrent loss, year after year, from this disease, can only be prevented by changing the location of the corral or by using another method of castration.

Where tetanus is prevalent in a herd and they cannot be moved to sanitary quarters, perhaps the best means of castration is the use of rubber bands placed tightly about the scrotum. If the bands are dipped in tincture of iodin before being applied they occasion no raw surfaces and tetanus does not follow castration by this method, even in the worst infected localities. However, this method of castration by ligating the whole scrotum is inevitably painful and should not be resorted to in any case except where the danger from tetanus makes it imperative. 


\section{CASTRATION OF SWINE}

Restraint.-With the exception of very large old boars, swine are generally confined in lateral recumbency for the castrating operation, and unless the animal weighs in excess of 200 pounds it may be held by an assistant without the aid of ropes or cords. The subject should be placed on the left side for the righthanded operator, the assistant holding the pig's right fore leg and hind leg together within the grasp of the hand as indicated in the eut. The assistant's knee rests upon the neck of the subject and with the left hand he holds the lowermost hind leg. If the animal is particularly vigorous and resistive, the operator may help to secure him by resting his left knee upon the uppermost ham of the subject.

Some old boars attain the weight of 700 pounds and more and when these large animals are castrated, the operation is performed while they are in a standing position, confined by means of a rope, the noose of which may be applied about the upper jaw; the other end of the rope being tied to a post. In most instances the animal resists confinement by pulling backward upon the rope sufficiently to keep it taut, and he is usually so oceupied in this manner that the operation can be done without the use of additional means of restraint. Because of the lact that they sometimes try to sciuat and seat themselves upon the buttocks in such a manner as to render the operation impossible, it be- 
comes necessary in these cases to resort to the use of a pole, which should be pushed under the flanks and serves as a lever of the second class, preventing the animal from assuming the sitting posture.

Technic. - The scrotum should be thoroughly scrubbed with a 2 per cent solution of Liquor Cresolis Compositus before being incised, although in the majority of eases for ordinary practical work, this precautionary measure is not taken. Because of the manner in which swine are usually liept, it is doubtful if this semblance of preoperative cleansing is of any benefit when castrated animals are returned to their unsanitary and filthy pens as soon as the operation is completed.

A good, free incision is made through the skin and dartos parallel to the median raphe, taking care to open the scrotum sufficiently low to insure perfect drainage of the wound. This clear drainage is most important for the prevention of post-operative disturbances such as infection resulting in scirrhus cord, of which we shall make mention later.

The uncovered operation is employed in the norma! animal and the testicle exposed by means of one bold incision. The attachment of the cremaster muscle is severed, allowing the ready withdrawal of the spermatic cord, and in very young animals the operation is completed by exerting forcible traction on the cord, causing its division by a sudden jerk which at the same time produces hemostasis. In old boars ablation of the testicle is done by means of the emasculator, or unlimited torsion may be employed and the cord divided by scraping with the knife.

After-Care-No especial after-care is required except that the castrated animals should be placed in clean quarters, or preferably kept at grass. Access 
to dust wallows and old straw stacks should be prevented, as this is a source of much serious infection.

\section{Sequelæ}

Castration operations in swine are seldom attended by severe hemorrhage, as spontaneous hemostasis usually takes place before an alarming loss of blood has occurred. In the case of old boars there is evidenced some manifestation of shock following the operation, which is characterized by more or less restlessness and symptoms of colic. Such patients should be allowed absolute quiet and no other treatment will ordinarily be found necessary.

Scirrhus Cord.-This affection is relatively common and develops where animals so affected are not given proper attention early. A general unthrifty condition of the animal follows which sometimes results fatally. It is well, then, for the operator to note the sources of this ailment.

Causes.-Perhaps the most frequent contributing factor to the etiology of this condition is the making of a scrotal incision that is not sufficiently large, or is located at a point that is decidedly too high to permit the cscape of wound secretion. Also, if the spermatic cord is divided too near the testicle, allowing the amputated end of the cord to become adherent to the scrotal wound margins and thus exposed, infection of this structure ensues with the formation of a scirrhus involvement which attains bulky proportions resulting in rapid depletion and emaciation of the subject.

Treatment.- When handled early hefore much hypertrophy of the cord and attendant necrotic involvement of adjacent tissues has taken place, prompt re- 
covery is stimulated by the making of a free incision into the tissues, exposing the affected cord, and the removal with a curette of the necrotic tissue followed by the injection of tincture of iodin. Where a large encapsulated mass exists indicative of much tissue proliferation, there is need for either complete removal of the degenerated structures or their destruction by means of chemicals. In cases where the diseased cord and surrounding hypertrophic mass attain very large proportions, the complete surgical amputation of such structures is accompanied by fatal shock in many instances. Experience has taught that in cases where the scirrhus cord constitutes as much as eight or ten per cent of the body weight of the subject, its complete removal by surgical means is likely to result fatally. These cases are therefore best treated by making a free opening into the encapsulated mass which is adherent to the end of the cord, and allowing escape of the usually ichorous contents. This having been done, the cavity may be packed with three or four drams of powdered copper sulphate, which is held in place by means of absorbent cotton. Injection of tincture of iodin following this first treatment in about two weeks is sufficient to bring about complete recovery in most cases.

Where the diseased cord with proliferation of tissue has assumed the form of an encapsulated mass that is not too large, the surgical removal by dissection and amputation of the diseased stump of the cord with the emasculator is indicated. The cavity should be packed with sterile gauze which is retained in position by means of scrotal sutures, the gauze to be removed in 24 hours. No further after-care is ordinarily necessary. 


\section{Scrotal Hernia}

Occurrence.-This condition is of frequent occurrence in swine and is noticed at or soon after birth, probably 90 per cent of all cases being congenital. A small percentage of cases manifest the condition a few weeks after birth, and sometimes this state may not be noticeable until the animal is about two months old, such eases being undoubtedly the result of injury, with a hereditary predisposition probably as a contributing factor.

Classification.-For convenience, hernix of swine shall be regarded in two classes: intra-vaginal, which comprises the major portion of all eases, and extravaginal, or interstitial, the more uneommon. The intravaginal hernia is a condition where the protruciing portion of intestine is lodged alongside the cord between the tunica vaginalis intima and tunica vaginalis reflexa. In such eases the tunica vaginalis reflexa is intact, and the bulk of intestine extending as far as the scrotum may be quite considerable, or, as is often the case, the herniaed mass may be very small.

In extra-vaginal or interstitial hernia there exists a rent in the tunica vaginalis reflexa permitting the protusion of the ectopic intestinal structure in the interstice outside of the tunica raginalis reflexa. Depending upon the exact location of the rent in the tunica vaginalis reflexa, it becomes necessary to modify the technique for the correction of the ailment. If the rent happens to be situated near the inner abdominal ring, the eovered operation for castration usually done will not serve to reduce the condition. In such cases the ligation of the cord including the raginal sheath will not close the rent, it being situated anterior to the 
point usually chosen for the application of the ligature.

Treatment.-The method of correcting this condition is essentially surgical, and affected subjects should be cared for when about a month old. It is possible to defer the handling of such cases until the animals weigh from 60 to 75 pounds, but it is more desirable in every way to operate on suckling pigs while they are very young.

Preoperative preparation consists of withholding all diet from 12 to 24 hours. They should be kept in clean quarters to render more nearly possible a thorough cleansing of the surgical field.

Anesthesia.-No anesthesia is ordinarily employed in the performance of this operation, although the administration per rectum of a solution of fifteen grains of chloral hydrate dissolved in an ounce of water, twenty minutes before operating, is advisable. This will produce sufficient depression to minimize pain and greatly lessen struggling and resistance.

Restraint.-When subjects weigh 25 pounds or less, they may be confined by hanging them over a partition or board fence by means of cords or straps attached to the hind legs, with the animal's belly presented toward the operator. Larger animals may be restrained upon an improvised table or door, tilted at an angle of about 45 degrees, allowing the head to hang lowermost, thus favoring gravitation of the viscera toward the diaphragm. This position is more comfortable for the heavier animals and also adds to the convenience for the execution of the technic.

Technic-In cases of intra-vaginal hernia where the amount of intestine protruding is not great, and 
the subjects are treated while young, the ordinary covered operation for castration is indicated.

The scrotal region is thoroughly scrubbed with soap and water if much soiled. If the animals have been kept in clean quarters, it is only necessary to scrub off the parts with a little gasoline or alcohol and then paint with tincture of iodin. An incision parallel with the median raphe is made through the skin and dartos, and carried very low to favor drainage and also to permit the application of a ligature closer to the imner abdominal ring than would be possible were the incision made at the usual site.

After haring exposed the vaginal tunic by a careful dissection, the areolar tissue is broken down, severing the attachment between the tunica vaginalis reflexa and adjacent structure. This dissection must be carefully done to avoid injuring the vaginal tunic, which is generally very delicate. It is not desirable to rupture this structure until it has been severed free from adjoining tissues to a point along the inguinal canal under the pubis. Dissection having been completed, the testicle is seized while confined within the vaginal tunic, and a heavy pair of compression forceps are clamped over the cord and its enveloping tissue, as high up as possible, taking care that no portion of intestine is confined within the grasp of the forcep. This having been done, a needle armed with a stout piece of sterile silk is passed through the cord and carried entirely around the cord and its coverings, and securely tied. Amputation of the cord at a point about an inch from the ligature is then effected and the scrotal wound is closed with a continuous suture of heavy silk, leaving a small opening at the lowermost 
point tor drainage. No especial atter-care is necessary in these cases.

Technic for the Correction of Extra-Vaginal Hernia.-In cases of extra-vaginal hernia, or in any case where the amount of intestine protruding into the vaginal tunic adjacent to the testicle is considerable, it becomes necessary to execute a different operation than the one heretofore described.

The animal should be restrained upon an inclined improvised table with the head lowermost, and given complete anesthesia of ether or A. C. E. The surgical area-region of the groin-should be cleansed with gasoline and painted with tincture of iodin. Serving as a guide, the inner abdominal ring may first be located by palpation, and an incision about four inches long is then made over this site and parallel with the course of the vaginal tunic. The tissues are divided by careful dissection and the upper inguinal region thus exposed makes possible the incising of the vaginal sheath, bringing to view the cord and intestine, provided the intestine has not returned into the peritoneal cavity by gravitation. The margins of the wound made in the raginal sheath are then seized with forceps and the hemia is reduced. The cord is secured and the testicle drawn outward and amputated with an emasculator or ligatured with gut and severed with scissors. After amputating the cord and trimming away any excess portions of the vaginal tunic, the cord is then pushed into the peritoneal cavity and the inner abdominal ring is closed by a four or five-point purse-string suture of sterile chromic gut. The skin wound is closed by means of silk sutures and no further attention need be given the subject except to provide clean, sanitary quarters, where they will be unmolested by other animals. 


\section{CASTRATION OF DOGS AND CATS}

Restraint and Anesthesia.- For this operation dow are restrained preferably on some sort of operating table where they may be muzzled and unless they are very large or vicious they may be held by one assistant. Anesthesia is not employed unless there exists some pathological condition which renders the operation painful and tedious. Sporting dogs sometimes receive injuries involving the scrotum and doing some damage to the testicles, necessitating the removal of one or both glands, and if attention has not been given to them until the structures have become greatly inflamed, the operation may be considered too painful to pertorm without anesthesia. In anesthetizing dogs, morphin, atropin, or H. M. C. may be given about an hour before administering chloroform or dilutions of chloroform, such as A. C. E.

In the handling of eats, the operator should ever remember that these subjects are nervous, highly sensitized creatures and require considerate, gentle care. For the purpose of castration, they should be confined by rolling them up in a blanket or heavy rubber sheet, and this must be done quickly to avoid an encounter which might result in injury to the operator. No anesthesia is necessary in the castration of the cat under normal conditions. If the operation for any reason, seems likely to be a difficult or severe process, the animal may be anesthetized with A. C. E. 
Technic--In dogs as well as in cats, the hair should be carefully clipped away from the scrotum before operating. In the long-haired cats, this is quite essential, and the surgical field should be eleansed with a mild antiseptic solution. The scrotal incisions are made parallel with the median raphe, exposing both testicles, as indicated in the uncovered operation, and this may be done before amputation of either of the glands is attempted. The distal attachment of the

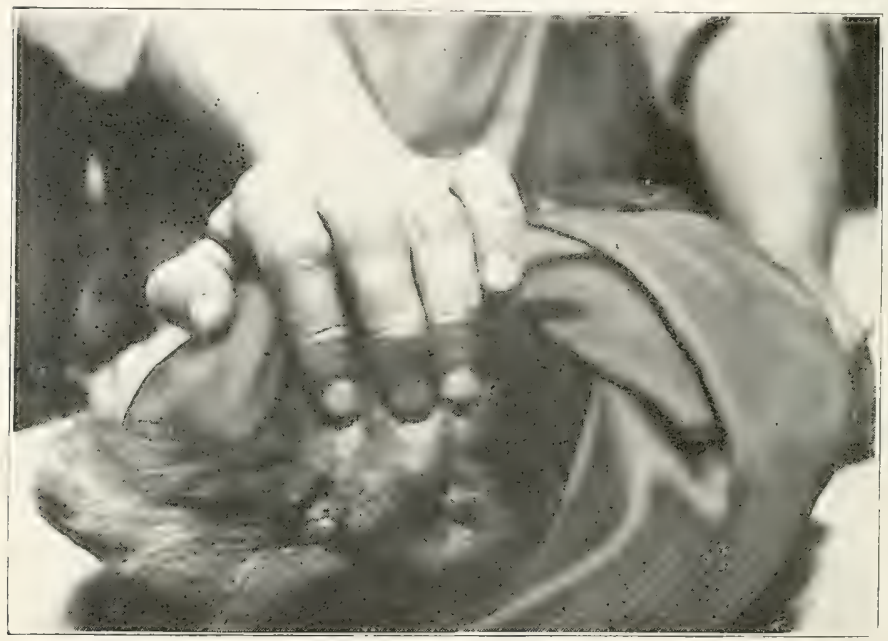

Fig. 15-SHOWING MANNER OF RESTRAINT OF MALE CAT FOR CASTRATION

cremaster muscle is serered which allows protrusion of the cord without resistance. Particularly is this essential in cats as it is then possible to obviate any danger of the amputated end of the cord becoming adherent to the scrotal wound margins and causing local irritation or subsequent infection of the cord.

The cord is preferably severed with an emasculator, or in cats, serrated scissors may be used. In the castra- 
tion of puppies there is no danger of serious hemorrhage, but in the adult operation where the emasculator is not employed, it is urgent to exercise care in the manner of division of the cord, to prevent hemorrhage.

Cats are preferably castrated when they are about six months of age, if in good health, and if the operation is done at this period, there is no attendant danger. In the adult or aged cat, hemorrhage is more likely to occur, although not to the extent that it is in the castration of dogs. Older cats sometimes suffer considerable shock and should be given 1-500 grains atropin sulphate twenty minutes before operating.

After-Care-For healthy, normal dogs, castrated in the proper manner, no after-attention is necessary, as the wound inflicted does not seem to occasion serious inconvenience and infection of any seriousness seldom ensues.

When possible, cats should be given the freedom of their accustomed haunts and left ummolested, for when confined in strange quarters they often become constipated. Local infection resulting in intoxication is likely to result fatally, if the subjects are not given careful post-operative attention. Sometimes because of local swelling, it is necessary to enlarge the scrotal incisions two or three days after the operation has been performed. Treatment in these cases consists in the removal of necrotic tissue with a curette, or simple irrigation with a mild antiseptic solution. To avoid complications a laxative diet should be given.

\section{Cryptorchid Dogs and Cats}

Cryptorchidy is occasionally found in these subjects and while the veterinarian is seldom called upon to 
operate, it is sometimes necessary to perform this operation even in localities where small animal surgery is infrequently done. The condition in these subjects is closely analogous to that encountered in larger animals. Ectopic testicles are sometimes found in dogs, and in one case handled by the writer, the testicle in a cat was so firmly adhered inside the inguinal canal that only with great difficulty was it removed.

Technic.-Preoperative preparation consists in the administration of a laxative, and if the rectum is filled with dry fecal matter, an enema is giren. The animal is put under a general anesthetic and confined upon the operating table in position for laparotomy. A liberal area is shaved in the pre-pubic region of dogs and in the flank of cats, and an incision made of sufficient length to permit of visual examination of the peritoneal cavity. The hidden testicle is sought by tracing its course from the uro-genital fold and when located is removed by limited torsion of the cord, or with an emasculator.

The abdominal wound is then closed by means of a continuous suture of No. 0 chromic gut, including the peritoneum and abdominal muscles. The skin and fascia are united by means of another continuous suture of silk, leaving a small opening at one end for drainage. With the exception of the drainage opening, the wound is sealed with flexible collodion, and the surgical field is covered with absorbent cotton held in position by means of a bandage.

No after-care is necessary other than to administer a suitable regimen and to take every precaution to prevent constipation. The skin sutures should be removed in five or six days and complete recovery generally ensues within ten days or two weeks. 


\section{CASTRATION OF BIRDS (CAPONIZING)}

The castration of the male fowl gives it a good market demand as a table delicacy, and when this operation is properly done at an early age, the capon attains abnormal development and the fiber and flavor of the flesh are greatly improved thereby.

Age.-The best results are obtainable by operating just before the combs are formed, or as early as it is possible to distinguish between the sexes.

Preparation of the Subject.-Withhold all food for 36 hours and water for 12 hours.

Restraint.-Arrange for the work a suitable table. One may be improvised by using the head of a barrel, covering it with a clean piece of oil cloth or rubber sheet. Confine the fowl by means of cords and suitable weights, grasping and holding the two wings within a noose with a weight attached to hang on one side of the table, and attaching a similar expedient to the feet, suspending this weight directly opposite the one which confines the wings.

Technic--Prepare the fowl by plucking a few feathers from the surgical area which includes the vicinity of the last intercostal space. In this manner enough skin is bared to allow of its being displaced sufficiently to make an incision in the skin, which, when the structures are released will not match or coincide with the next incision to be made between the last two 
ribs. After making this intereostal incision, a speculum is introduced gently for the purpose of separating the ribs, and with a good overhead light, the peritoneal cavity is sufficiently illuminated to permit a good view of the region of the testicles, which are light in color and just anterior to the kidneys and very close to the aorta.

Removal of the testicles is effected by means of adaptable snares or forceps, taking extreme care to include all testicular tissue within grasp of the instrument, so that not even a microscopic portion of the gland may be left attached. Sufficient secretion will persist if any testicular tissue is left in the situ, that the result is what is known as a "slip," or an imperfectly castrated bird. The operator should also be very careful to avoid injuring the aorta as fatal hemorrhage invariably results.

Some castrators remove both testicles from the same side, removing the one lowermost, first. However, the average operator finds it more satisfactory to make an incision on each side, removing one testicle at a time. Suturing of the wound is unnecessary, as the skin which has been displaced, when released, will cover the wound between the ribs.

After-Care.-No especial after-care is urgent other than that comfortable quarters with low roosts be provided, and the birds should be observed from 24 to 48 hours afterward as their movements may result in the entrance of air into the incision in some cases, and bloating occurs; the removal of air in these instances necessitates the puncturing of the skin. 


\title{
PAR'T T'WO
}

\section{CASTRATION OF FEMALES (SPAYING, OOPHORECTOMY, OVARIOTOMY)}

\author{
SECTION I
}

\section{VAGINAL OVARIOTOMY OF THE MARE (CHARLIER'S METHOD)}

Not infrequently it becomes necessary to eastrate mares for the correction of ailments involving the ovaries. The principal disturbance caused by degenerative changes in the ovaries, is nymphomania, which so often causes viciousness that mares thus affected are very unsatisfactory in service at the time of the estral period, displaying various undesirable traits such as kicking, biting and striking, and many of them are line grippers. Maniacal symptoms always predominate in these mares and their frequent stopping to eject small amounts of urine and the protrusion to view of the erected clitoris, makes them repulsive as well as harmful.

When consulted, veterinarians should urge the unsexing of such animals as it is the only sensible mode of correcting this condition. Other corrective operations have been performed, resulting in recovery in some cases, but they are not to be recommended. Am- 
putation of the clitoris has been known to cause the complete cessation of the manifestations of nymphomania, the pain and discomfort inflicted on the animal being sufficient to check the signs of sexual desire, but where there is involvement of the ovaries, such an operation is an irxational procedure inasmuch as it does not tend to remove the cause. Caudal myectomy has also been resorted to in line grippers to correct this vice, and while it effects a greater degree of safety in the driving of the mare, this, too, fails to reach the actual cause and except to correct the habit of line gripping is not to be encouraged. The condition of nymphomania still continues in spite of clitoridectomy or caudal myectomy.

Preparation of the Subject.-Mares should be given a purge 48 hours before the time set for the operation, and they should be dieted, receiving only very light concentrates, including bran.

Restraint and Anesthesia.-Subjects may be handled either in the standing position without complete anesthesia, or confined in recumbency and anesthetized with chloroform. The standing operation is preferable as it renders a good technic much easier of execution. Partial anesthesia may be accomplished by the administration of two or three grains of morphin given subcutaneously, and an ounce of chloral hydrate given per os in a capsule. These agents should be given about an hour before the operation is performed. The tail should be bandaged from the base outward for about eighteen inches and then tied to one side. For restraint a stanchion or stocks may be employed, or the mare may be held by means of a hippo-lasso and twitch. If confined within a stanchion, a cross bar should be placed just a little higher than the hocks, and the 
subject crowded back to assume a position in close contact with the cross bar, precluding the elevation of the hind legs which might encinger the operator and injure the animal as well. The subject should be prevented from lying down by means of girths, and a rope or strap should be passed over the back.

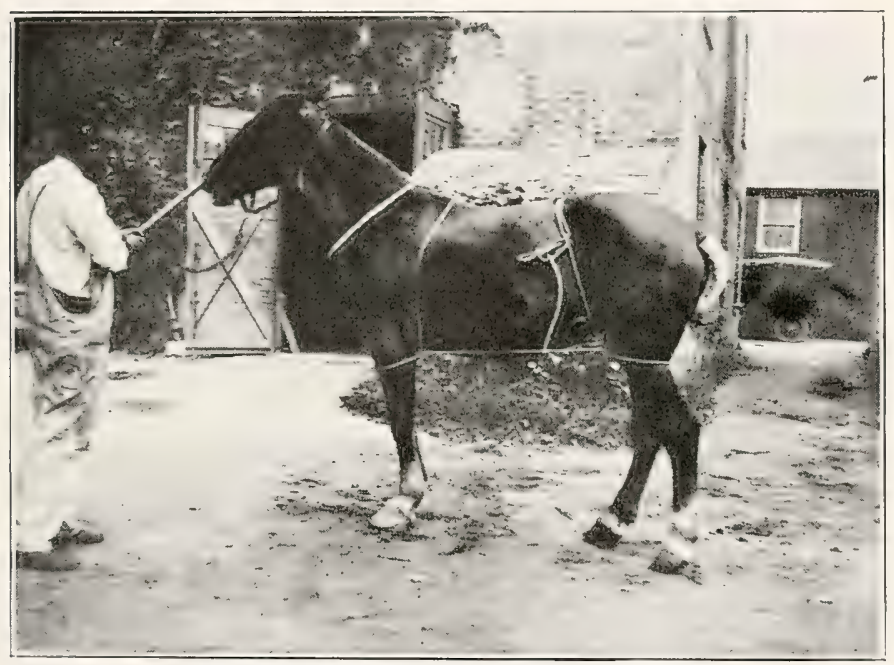

Fig. 16-A FORM QF HIPPO-LASSO

Illustrating a suitable mode of restraint for vaginal oophorectomy of the mare by means of a form of hippo-lasso as employed by the author.

Preoperative Preparation and Technic.-The external perineal region is then scrubbed with soap and water, and the vaginal canal irrigated with a one-half of one per cent solution of lysol. Pledgets of cotton may be used to swab out the vaginal canal, though this is not imperative.

The introduction of water in the vaginal canal stimulates a ballooning of its walls. This is a normal physiological function vested in this structure and makes 
the walls very tense - a condition which greatly facilitates the performance of the operation. In some mares this tensity of the vaginal walls does not continue for a very long time and while the injection of additional quantities of warm water may cause ballooning to recur, this procedure is unnecessary, as the operator can, by placing the end of a blunt embryotomy hook against the inferior vagino-urethral juncture, just below the external os, and gently pushing forward, tense the wall sufficiently to incise the vaginal wall with safety.

Making the incision through the vaginal wall is the most dangerous part of this operation, as it is easily possible to wound the aorta or one of the iliac arteries, if the utmost care and thought are not exercised in this move. As a matter of precaution these vessels should be located by palpation, this is readily accomplished as their pulsations are easily recognized.

Because of the changed relationship of the structures when the vaginal wall is ballooned, the knife is simply thrust forward, but if the wall is tensed by artificial means, the incision is made in an upward and forward direction, and under these conditions there is more likelihood of the large vessels becoming injured should the animal struggle when the incision is made.

The lubricated hand conveying an ordinary hooked castrating blade or other suitable knife, is introduced and an opening made in the wall very near the median line of the superior vaginal wall in the immediate region of the fornix; this incision should at first be long enough to permit the penetration of the finger, and may be enlarged by simply forcing the other fingers gradually, and finally the hand, through the vaginal wall into the peritoneal cavity. Caution should be 
taken to avoid separating the peritoneum from the muscular portion of the wall, lest a pocket or sac be formed which in retaining wound secretions would be likely to cause local post-operative infection and result in generalized septic peritonitis. There is little danger of doing injury to the vessels or to the rectum, however, if the operator uses a reasonable degree of care in his work.

Finding the Ovary.-The hand is pushed through the incision in the vaginal wall into the peritoneal cavity and thence turned downward and forward, and the body of the uterus may be readily located. The horns of the uterus bifurcate at almost right angles, and by tracing them out, the ovary is found suspended by means of the broad ligament; it is then secured within the grasp of the fingers and drawn into the vaginal canal if the ligament is sufficiently long or lax to permit this. In some mares the ovary seems to be suspended in a rather elevated position in the sublumbar region, and the broad ligament is really broad and short, making it impossible to bring the ovary down through the raginal wall into the canal. In such cases, it is best to twist the ovary a few turns causing the expansion of its supporting ligament to become grouped in a cord-like mass. This readily allows the structure to be grasped by the spaying emasculator or ecraseur, and facilitates amputation.

After having removed the ovary by means of a suitable spaying emasculator, it is confined within the hand and the other ovary is removed in the same manner. If it is possible-and it usually is - to draw the organ into the vaginal canal before amputating, it is left in the canal until both are severed; thus both are re- 
moved from the canal at the same time and the fiand is not withdrawn until the operation is completed.

After-Care.-No attentive after-care is necessary following this operation except that the animal should be observed for a few hours as colic sometimes occurs. Mares should be given a laxative diet and observed daily lest constipation result because of the pain which attends defecation for a few days after the operation.

Results.-In cases of chronic nymphomania in older mares where the condition has existed for a few years, complete recovery from it should not be expected immediately. The process is gradual and sometimes not completely satisfactory for a few months.

This operation has been performed under very adverse conditions in fillies eighteen months of age (normal animals) with results which justify the advisability of spaying in every case of nymphomania. Done with reasonable skill, the mortality from this operation is very low. 


\section{VAGINAL OVARIOTOMY OF THE COW}

The general reason for castrating cows is for the purpose of removing one or both ovaries when diseased. In certain cases of degenerative involvement of one or both of the ovaries resulting in the animals being "Bullers," cows are spayed with the object of fattening them for market. In some cases where one ovary becomes hypertrophic and considerably indurated as a result of cyst formation, and nymphomania develops in an otherwise good milk cow, it is advisable to remove the diseased gland. Some authorities claim that spaying, if done at the proper time, prolongs the period of lactation for several years.

This method of spaying is employed in animals sufficiently large to easily permit the introduction of the hand into the vaginal canal, and is preferable to making the flank incisions because there are no exposed wounds resulting. 'This technic may be employed with safety during fly-time without any especial after-attention.

Preparation of the Subject.-Food should be withheld for 24 hours and a purgative dose of magnesium sulphate given 12 to 18 hours before operating.

Restraint and Anesthesia.-Animals are preferably confined in the standing position within a stanchion or narrow stall, it being unnecessary ordinarily to resort to the use of ropes or other appliances to further hold the animal if the head is closely and securely fastened. 
One to one-half ounces of chloral hydrate dissolved in a quart of water given as a drench twenty minutes before the operation is begun will serve to diminish sensibility very materially.

Technic.-The tail should be tied to one side and the external perineum thoroughly cleansed with soap and water and the vaginal canal irrigated with a onehalf of one per cent solution of lysol in warm water. In cows it is necessary to employ a vaginal speculum or to use other means for tensing the wall, as it does not balloon as in mares. The wall having been tensed, which may be done as described in the chapter on spaying mares, the operation is conducted exactly the same as this operation on a mare, the operator remembering, however, the difference in the disposition of the uterine cornua, and that the ovaries are suspended in a somewhat different manner than in the mare; yet, by tracing out the horns from the body of the uterus, no difficulty should be encountered in locating the ovaries.

After-Care and Results.-No after-care is necessary ordinarily. The animal should be allowed a moderate degree of exercise and given a laxative diet. In animals that are chronic "Bullers," where there is a sinking of the sacro-sciatic ligament, a flaceid condition of the vulva and the existence of almost perpetual estrum, it is not reasonable to expect that the removal of a diseased ovary will effect a complete correction of the ailment. 


\section{CASTRATION OF HEIFERS}

The current demand for desirable breeding animals has reduced the practice of castration of heifers, a procedure quite common in the past. It is not done extensively at the present time, except in a lew instances where range cattle are spayed to avoid the confusion of brands - the obvious result if "open" heifers were sold and put at large on the ranges. This operation is also necessary at times for the profitable feeding of virgin females for market.

Age.--The best age for spaying heifers is before their first estral period, but since this operation is done by the flank route, it is sometimes impossible, as their first estral period may manifest itself during midsummer, and it is not best to operate during fly-time if it is possible to do it at any other time.

Preparation of the Subject.-Heifers at grass require no preoperative preparation except the withholding of food for 24 hours and water for about 12 hours preceding the operation. 'This allows sufficient time for' the evacuation of most of the intestinal content and makes for a more comfortable handling of the case, for both the operator and the subject.

Restraint.-Animals should be confined either in the standing position or in lateral recumbency. If handled in the standing position, and large numbers ar to be spayed at once, it is advisable to build a suitable 
chute, this chute connecting by means of a long runway with a small lot or corral, enabling the expeditious management of large numbers without undue delay or accidents.

The head should be held by means of stanchion bars, and the animals may be prevented from lying down by means of girths or cross bars. A gate should be provided for on the side of the chute to permit ready access to the flank of the subject.

When animals are handled in large numbers in the recumbent position they are usually confined by means of ropes with the aid of saddle horses and are cast and "stretched." A rope about the neck including one or both front feet, is held taut also by means of a horse and rider, and another rope about the hind legs serves to confine the animal on its side. This position, however, has the disadvantage of over-tensing the abdominal muscles, and it is preferable to secure the upper hind leg only. This may be done by an assistant holding the same as illustrated in the accompanying cut.

Preparation of the Surgical Area.-In young heifer's, it is best to operate on the left side, but in larger animals, because of the bulk of the rumen, it is perhaps found easier to invade the right flank.

The hair is clipped from a liberal porition between the external iliac angle and the last rib, just below the transverse lumbar process, and this area is scrubbed with a two per cent solution of Liquor Cresolis Compositus or some other suitable antiseptic.

Operative Technic.-An incision is then made with some good spaying knife through the skin and fascia, of proper length to enable the ready introduction of the operator's hand. It is a matter of personal choice as to which particular style of instrument is to be 
employed in this operation. The skin having been incised, the point of the knife is thrust into the abdominal musculature for a sufficient depth to allow the introduction of a finger into the structures for the purpose of separating muscular fibers and these are separated by forcing the hand through the structures. It is wise to avoid transverse division of the muscular fibers, more prompt healing of the wound results if the intercrossing muscular fiber's are not severed, as spontaneous closure of the incision occurs almost immediately after the hand has been withdrawn from the peritoneal cavity.

The ovaries are sought by introducing the hand into the peritoneal cavity, keeping it in immediate contact with the parietal peritoneum and turning the hand in a backward direction toward the shaft of the ilium. For the beginner this may serve as a landmark, and he may carry the hand from this point to the pubis, there locating the bladder; and immediately above the bladder, the body of the uterus is easily found. By tracing out the bifurcating cornua, the ovary situated opposite the point of entry is first secured and amputated by means of suitable scissors or spaying emasculator. The instrument is introdueed alongside the forearm of the operator, and the amputation of the ovary is done within the peritoneal cavity. The remaining ovary is removed in a like manner and the hand is withdrawn then, bringing both glands with it.

The abdominal muscles and peritoneum are not sutured. The skin and fascia are united by means of two or three interrupted sutures of heavy linen or silk material. This is done by means of a large, heavy spear-pointed needle, and this part of the operation may well be delegated to an assistant where animals are handled in large numbers. If it is necessary to 
operate in fly-time, the wound should be covered with pine tar and no after-care given except that the animals should not be allowed the run of premises where it is possible for them to overeat. They should be carefully herded for the first 24 or 48 hours in order to prevent their being obliged to travel any great distance for food and water.

Results.-Mortality from this operation is very low. Facts show that in competent hands, the fatalities from restraining and handling of the animals are far oreater than those caused by the surgical operation or seque $æ$ directly resulting therefrom. The losses may be estimated at from one-fourth of one per cent to two per cent where conditions are favorable. 


\section{CASTRATION OF SOWS}

As has been said of heifers, the increased demand lor sows suitable for breeding purposes has led to a noticeable conservation of these animals. The females of better stock are too valuable for spaying, generally, and those that are fed for market are usually fattened before the estral period attending puberty materially interferes, or else they are bred while being fattened.

Preparation of the Subject.-Food and water should be withheld 12 hours before operating, and the animal should be kept in clean quarters for a certain limited time prior, so that the skin may not be in a badly soiled condition.

Age for Operating. - Sows are best handled from two to four months of age.

Restraint.-The animal should be confined upon some suitably improvised operating table which is positioned in a sloping manner to canse the head of the subject to hang considerably lower than the hind quarters, and either the right or left flank of entry is convenient.

Preparation of the Surgical Area.-The hair is then clipped from a liberal space in the flank region anterior to the external angle of the ilimm, and the field cleansed by means of a swab and gasoline and immediately painted with tincture of iodin.

Technic.-In small sows, an incision of sufficient size to admit one or two fingers, is made through the skin, fascia and abdominal mucles. With large adult 
animals, it is necessary to make an ample opening for the introduction of the operator's hand into the peritoneal cavity.

The ovaries then are sought and will be found in much the same manner as described for the castration of other females, being attached to a very long and lax broad ligament which will permit of their being brought to the surface and amputated on the outside of the peritoneal cavity. The skin and abdominal muscles then should be united by means of from two to four interrupted sutures, using braided silk for this purpose. It is not essential to suture the peritoneum. The wound should be covered with pine tar and no after-care is necessary except that the animals be given freedom of clean quarters, preferably at grass, and where other animals will not molest them. 


\section{CASTRATION OF THE DOG (SPAYING)}

A veterinarian's ability as a general practitioner' is often estimated by the results he has achieved in the unsexing of female dogs and there are few operations that he is called upon to perform which are more likely to bring him into disrepute among his clientele if the outcome is not perfectly satisfactory in every respect. As there are some cases where the execution of a good technique is almost impossible where the operation is done without proper facilities, by one not thoroughly accustomed to doing it, it therefore behooves the veterinarian to familiarize himself. with every detail of this operation.

Females of the canine species, especially those of the larger breeds which lead an outdoor life, should certainly be castrated if undesirable for breeding purposes. This applies also to female house dogs in the city which not only are a source of a sreat deal of annoyance in a neighborhood, but are likewise very troublesome to their owners, if not closely confined at certain periods. Moreover, the promiscuous gathering of all sorts of males occasioned by a female at large when in heat, constitutes a direct menace in the spreading of various diseases such as distemper, mange, and even rabies.

Age for Operating.- Inimals that are in a healthy condition are generally operated on between the ages 
of six and nine months, and there is no good reason why it should not be done at even an earlier age. In collies or certain breeds of watch dogs, spaying is best done at the age of six months, as there is a tendency toward the accumulation of too much fat when this operation is deferred until the subject has matured.

Operating during the estral period should be avoided if possible. While estrum is manifested by a congestion of the vulva, yet marked congestion of the ovaries and oviducts persists in some cases for weeks after external signs of estrum have subsided.

\section{Anatomy of the Structures Directly Concerned.-}

Since these animals are multiparous, the uterine cornua are well developed and the body of the uterus is small and rather undeveloped. The horns are supported by the broad ligaments which are of sufficient growth usually to permit the ovaries being readily drawn to the surface of an abdominal incision made at the linea alba. The ovaries are almost completely encapsulated within the broad ligament; the size of the oviducts varies materially in different subjects and not in proportion to the size of the animal, - those having been pregnant possessing oviducts proportionately larger than those found in puppies not having reached the age of puberty. During the estral period, the oviducts, because of their congestion, are very large, and this fact serves to confuse the inexperienced operator whose tactile sense has not been trained to guide him.

There are no other structural differences of the genitalia sufficiently important to warrant further consideration.

Preparation of the Subject.-Where the operation is performed in a hospital equipped with proper facilities for the safe handling of animals, the subject should 
be given a bath, food withheld for 24 hours, and the intestinal tract emptied by giving a dose of castor oil, and later enemas.

Animals should not be confined within a cage continuously during the process of preoperative preparation, but should be taken out to encourage urination and defecation.

There are occasions when the veterinarian is obliged to operate without the advantages of hospital facilities and sometimes he is required to perform the operation when he cannot give the patient proper preparation, but this has been done with good results in the more hardy breeds; however, in view of the possibility of an unsatisfactory outcome, it is not wise to follow this practice even in the cases of animals having the more rugged constitutions.

Restraint.-The subject should be muzled and confined on an operating table or the body suspended by means of tapes which are looped about the hind legs and hung upon nails driven in a wall. If a table is arailable, the position of the animal may be changed with ease and this greatly facilitates the execution of the operative technic in that the tension of the muscles of the abdominal wall at the site of operation may be diminished if necessary, by changing the position of the body from perpendicular to almost horizontal.

Anesthesia.-This is one operation where there is every reason for the employment of anesthesia of some kind, and yet it is a deplorable fact that many animals have been barbarously handled by inhumane operators none too skillful in this branch of surgery. None of our patients tolerate morphin or anesthetic compounds containing morphin better than dogs, and there is no 
excuse for any veterinarian not employing morphin or some compound containing it, even though he has no

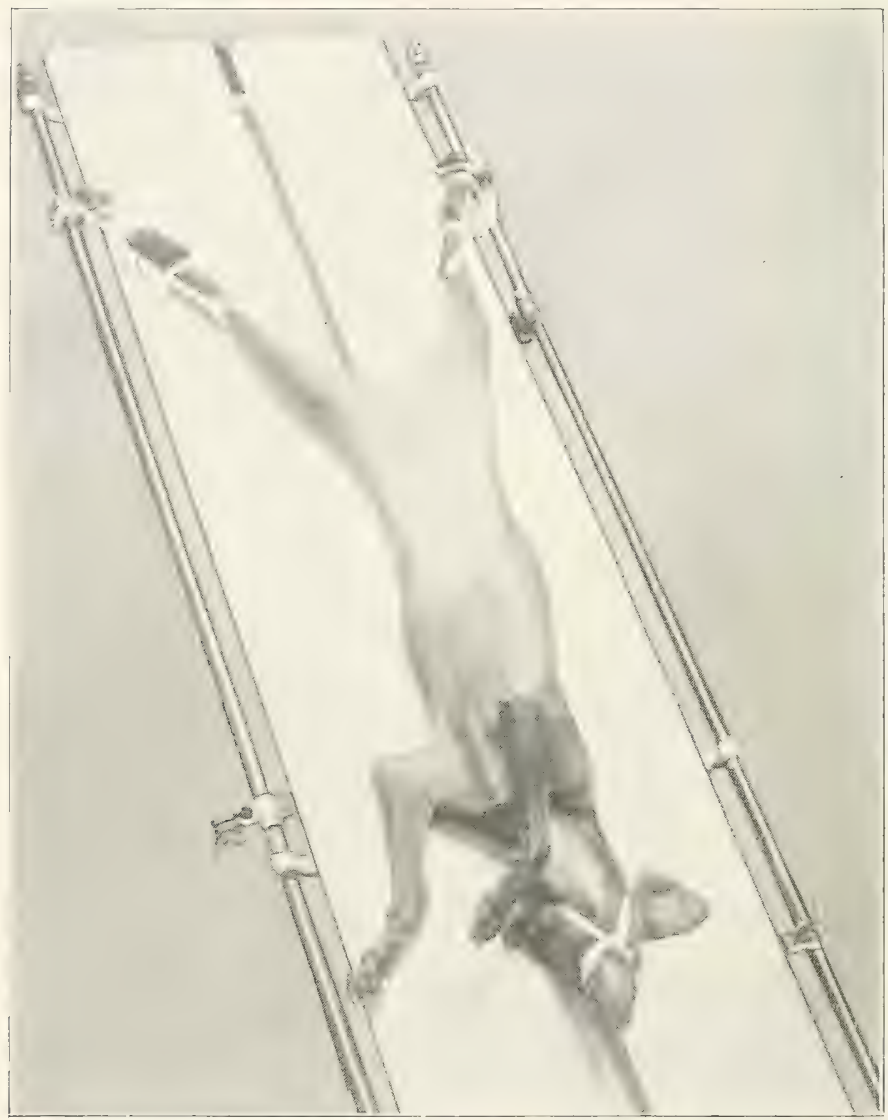

Fig. 17-THE ABOVE REPRESENTS A PRACTICAL MODE OF RESTRAINT FOR SPAYING. THE SUBJECT SHOWN IS UNDER COMPLETE ANESTHESIA

skilled assistant at hand.

H. M. C. has proved a very satisfactory agent, or 
when available, a morphin and atropin combination given subcutaneously about an hour before operating, is a good practice. The amount of morphin given varies somewhat with different operators, but from one-half to one grain of morphin with 1-100 grain atropin may be given animals weighing about 25 pounds, or larger doses may be used with safety where no other anesthetic is used. The administration of morphin an hour before the operation, usually causes sufficient nausea and retching to empty the stomach,a very desirable effect in a subject that has not been prepared for the operation. Where a trained assistant is obtainable, anesthesia is completed by the administration of either A. C. E. or chloroform.

Care should be taken during the administration of the anesthetic, as a sudden change in position of the subject from the horizontal to the vertical with the abrupt throwing of the weight of the intestines upon the diaphragm, is likely to cause arrest of respiration. Where no operating table is in use, the position of the body should be shifted gradually, and where animals are simply hung by the hind legs, the change of position must be accomplished with care.

Preparation of the Surgical Field.-For a linea alba incision, a liberal area in the prepubic region is lathered and the hair shaved from a space from two to four inches wide, extending as far forward as the xiphoid cartilage. The soap is then removed with a mild antiseptic solution and the skin dried and painted with tineture of iodin. Towels may be folded in such manner' as to cover all the mnshaved area, and these may be suspended by means of intestinal clamps or other forceps having limber jaws, by elamping the towels upon the skin over the region of the tensor fascia lata. 


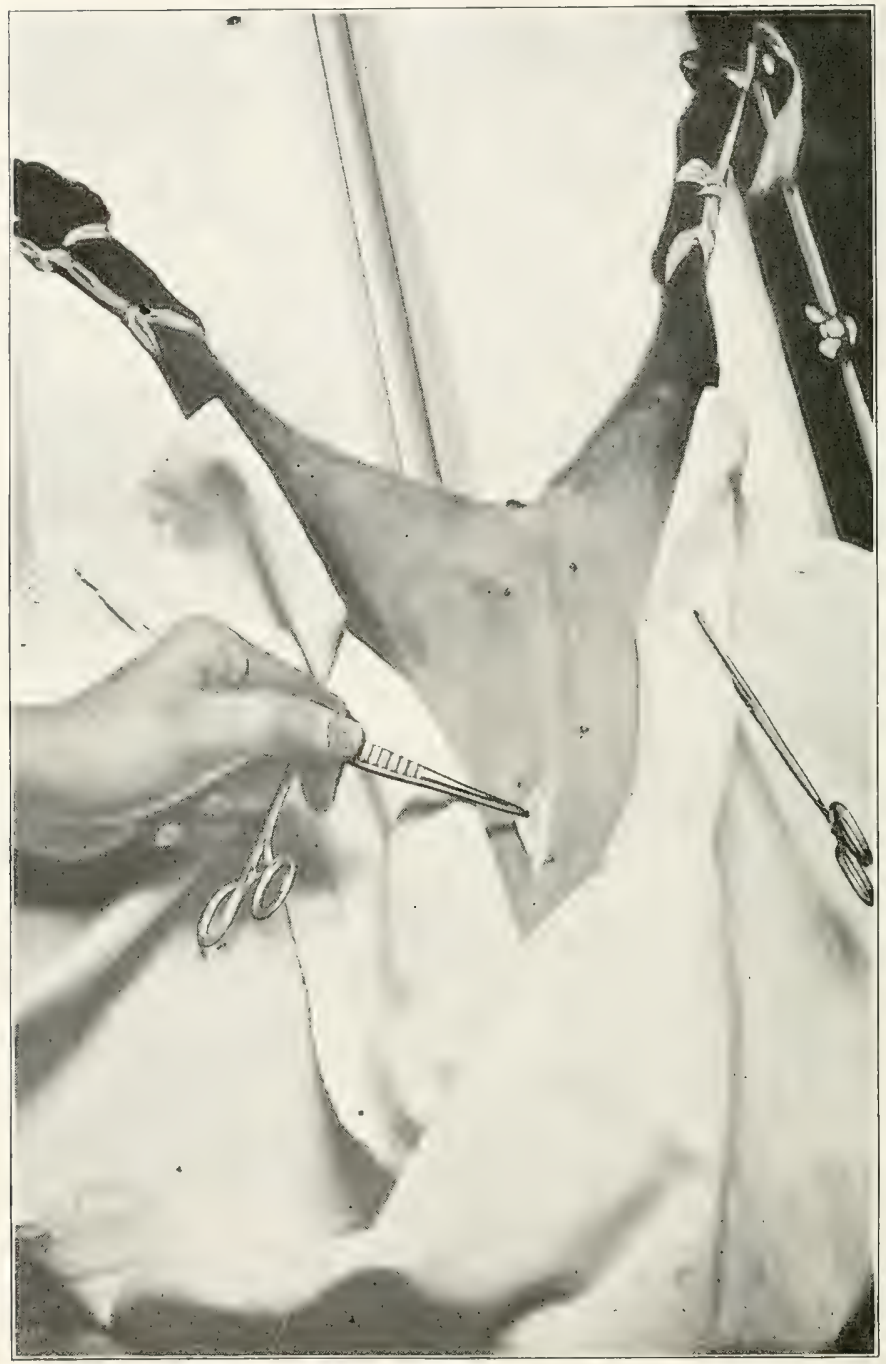

Fig. 18-SHOWING MEDIAN LINE INCISION, IMMEDIATELY POSTERIOR TO THE UMBILICUS 
Operative Technic.-A median line incision is made which is carried forward to the umbilical cicatrix. This incision is generally made an inch and a half in length though in some instances a two-inch incision is preferable. The tissues are divided carefully, and by means of dressing foreeps one of the wound margins may be drawn aside, enabling the operator to closely observe and recognize the tissues as they are exposed and divided. Some animals possess considerable fat which lies betreen the subcuticular fascia in the abdominal muscles, and this interferes somewhat with the vision of the line of incision as it is carried through the abdominal muscles. In such cases, one may remove a portion of this fat by means of scissors, or an assistant may, with the aid of a pair of forceps, retract the wound margins enabling the operator to observe and recognize the tissues as they are divided.

After having exposed the peritoneum, this may be punctured by means of a tenotome, taking care not to injure the bladder should it be greatly distended and lying immediately in contact with the peritonem at the site of the incision. Following the perforation of the peritoneum, the incision may be enlarged by use of peritoneal scissors or with the aid of a grooved director; by lifting and tensing the peritonemm, it is readily divided with the scalpel or tenotome. It is best to avoid enlarging the peritoneal opening by tearing as this makes it impossible to control the direction of the rent and an oblique or even a transverse rent may be produced which is rather difficult to suture properly.

Finding the Ovaries.-Two general methods are employed for locating the ovaries-one by retracting the wound margins, exposing the viscera to view and seizing the uterine horns with forceps withdrawing the 
ovaries without introducing the fingers into the peritoneal eavity. The other method consists in the introduction of the index finger into the cavity, and by tactile sense, seeking and removing the structures. It is a matter of opinion with different operators as to which method is preferable, so we shall describe the latter one, just mentioned.

The index finger is introduced into the peritoneal cavity, and for the begimmer it is well to at once locate the bladder which lies direcly in contact with the floor of the abdomen in the prepubic region. In some cases the bladder will be found to ba greatly distended and here it is well to apply a quantity of absorbent cotton against the external genitals, lest manipulation cause evacuation of some of its contents and add this possibility of contamination to the exposed wound margins and peritoneal cavity. After locating the bladder, the operator will readily find the body of the uterus lying just dorsally thereto; following out the uterine horn from its bifurcation, it may be crowded against the parietal peritoneum and brought to the surface and by employing traction upon it, the ovary is then carefully drawn out of the cavity for amputation. In some cases, because of the close attachment of the ovary, it becomes necessary to arch the spinal column of the subject to enable the withdrawal of the ovary to the wound surface to avoid undue tráction upon the structures which might result in rupture of the broad ligament and possible retention of some ovarian tissue or unnecessary hemorrhage.

As soon as the ovary has been brought to the surface of the abdominal wound, it is seized by means of suitable forceps and twisted in such manner that the oviduct and suspending broad ligament are brought in 
immediate contact and quickly clamped with a heavy pair of dressing lorceps. The operation is completed by limited torsion accomplished by twisting with the spaying forceps and an intrascapular ablation is in this manner effected. The remaining ovary is removed in the same manner and in cases where no marked congestion of the ovary and oviducts exists, as is obvious

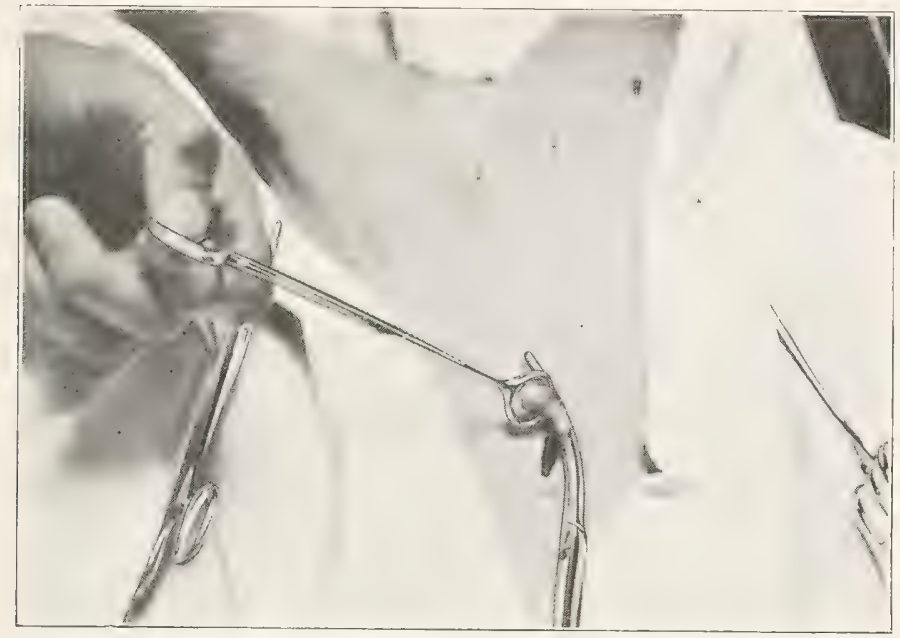

Fig. 19-THE OVARY, HAVING BEEN BROUGHT TO THE SURFACE, IS SHOWN CONTAINED WITHIN THE GRASP OF THE SPAYING FORCEPS; A PORTION OF THE BROAD LIGAMENT AND THE OVIDUCT ARE SECURED BETWEEN THE JAWS OF COMPRESSION FORCEPS

during estrum, this method of removal of the ovaries positively prevents serious hemorrhage.

Where it is found upon exposing the ovaries that the structures are greatly enlarged and congested because of the remaining effect of estrum, it is well to ligate with gut suture material, the broad ligament including the ovarian artery proximal to the ovary. Also an- 
other ligature is applied about the oviduct and intra. capsular ablation of the ovary is effected with scissors. In this way hemorrhage is controlled by ligation en masse of all structures on either side of the ovary.

After the stumps of the amputated oviducts are returned to the peritoneal cavity, the abdominal wound is closed by means of two rows of sutures. The peritoneum and abdominal muscles are scized by means of

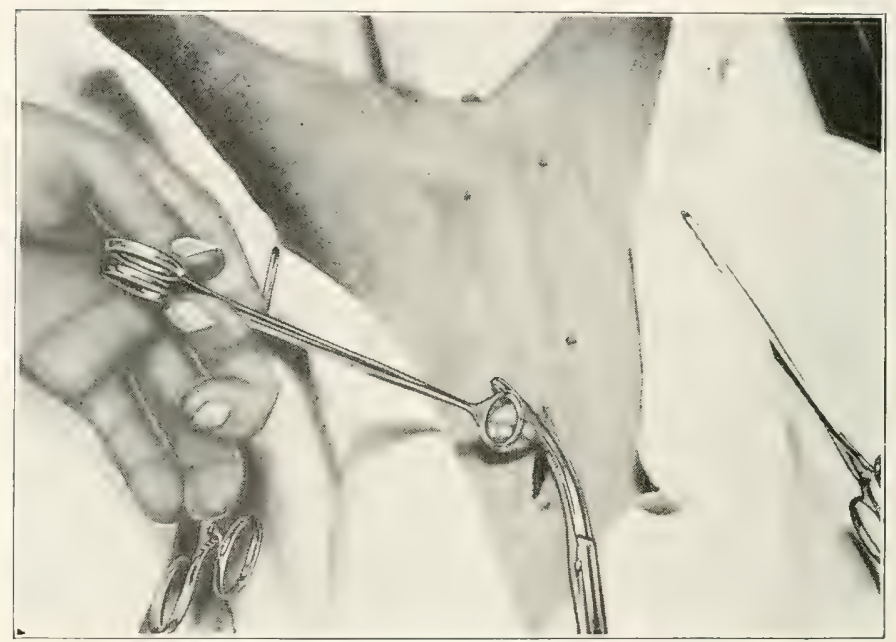

Fig. 20-COMPLETING THE PROCESS OF LIMITED TORSION FOR AMPUTATION OF THE OVARY

tissue forceps and with full curved needle armed with sterile gut No. 0, a continuous suture is made, including both the peritoneum and the abdominal muscles. The skin and fascia are united by means of a continuous suture of sterile silk or chromic gut No. 2, leaving at one commissure a space of about one-eighth of an inch in length unsutured, for drainage. A drainage opening is not imperative where a perfect technic is exe- 
cuted, as union by first intention should result. The skin. wound should then be sealed with flexible collodion, with the exception of the small opening (where an opening for drainage is provided for), for the escape of wound secretion should any infection occur.

The wound is then covered with sterile absorbent cotton which may be held in position with a many-tailed bandage or by means of a fold of sterile gauze, this to

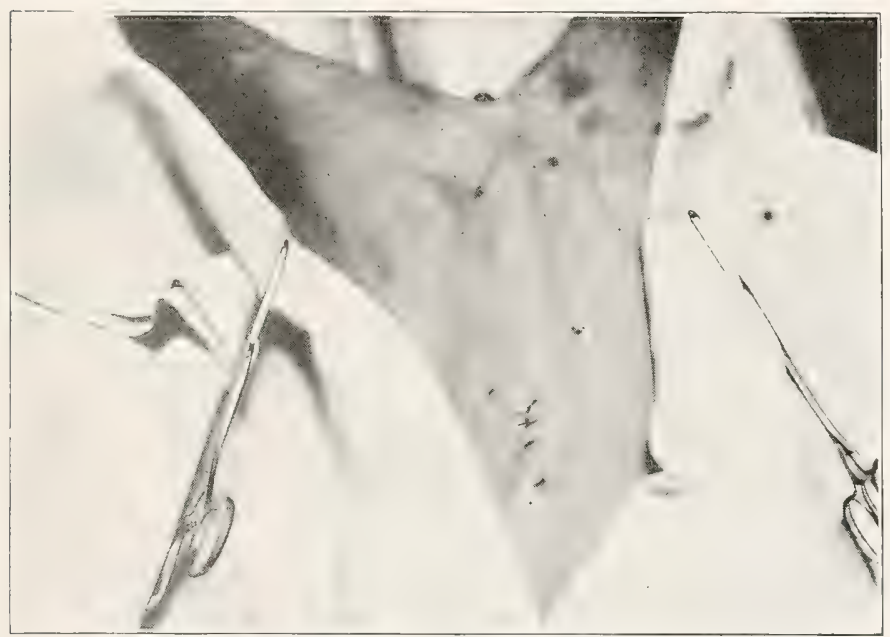

Fig. 21-SUTURE FOR COAPTATION OF THE PERITONEUM AND ABDOMINAL MUSCLES IS SHOWN IN POSITION HERE

be made secure with strips of adhesive tape encircling the body.

After-Care-The wound should be carefully inspected after 48 hours, and if there is any evidence of infection, gentle manipulation may be employed to force secretions out of the small opening which has been left for this contingency, taking care not to interfere with existing primary mion of tissue else- 
where. Where no provision for drainage has been made and infection has occurred early, surgical removal of pus should be done that no interference with primary union exists. The slin suture should be removed in four or five days. The animal should receive a light laxative diet following this operation and modcrate exercise permitted.

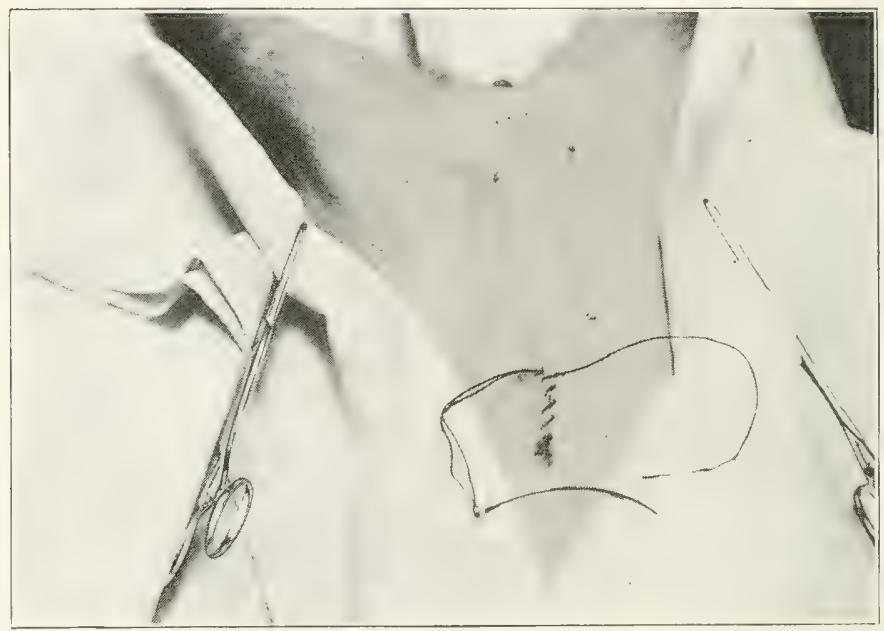

Fig. 22-THE SKIN AND FASCIA HAVE BEEN JOINED WITH A CONTINUOUS SUTURE WHICH IS FIXED BY TYING TOGETHER THE SINGLE END OF THE THREAD ON ONE SIDE WITH THE DOUBLE END ON THE OTHER

\section{Sequelæ}

Shock.-While the operation is in progress, manifestation of shock is sometimes noticeable, and very careful attention to the administration of the anesthetic is necessary, especially in the case of delicate animals as certain breeds of toy dogs, or those of the more highly sensitive organism. The preoperative administration of atropin is very beneficial in that the respira- 
tory center is stimulated and fatal shock is generally avoided. Where good surgical anesthesia is difficult to maintain, as it is in some cases, the application of heat by means of a hot water bag applied to the spinal column, is of obvious benefit.

When respiration is suddenly arrested, the operation should be discontinued at once and the abdominal wound hastily closed by clamping the margins of the skin together with a hemostat, and if the heart has not actually become quiet, artificial respiration should be quickly employed. Rhythmic traction of the tongue may be of service and inhalations of aqua ammonia are beneficial.

Hemorrhage.-In occasional cases, post-operative hemorrhage occurs and persists until the patient is wakened to such a degree that death results in from 24 to 48 hours after the operation. This sometimes happens in subjects that have been operated upon before the expiration of the estral period and where amputation of the ovaries has been effected without due regard to ligation or careful execution of hemostatic means by torsion.

Where capillary hemorrhage continues in sufficient degree to cause the escane of a quantity of blood in the peritoneal cavity without its assuming immediately dangerous proportions, the administration of from 1-250 to 1-50 grain of atropin subeutaneously, will be found very helpful. Such hemorrhage is not likely to prove fatal.

Infection.-The operator should cons.antly bear in mind the urgency of cleanliness in this work. While these canine subjects are quite resistant to infection, yet some cases of fatal septic peritonitis have been prodnced by general practitioners not having the essential 
regard for the importance of asepsis, who by neglecting to attend to the thorough eleansing of the hands, bring to their work the unnecessary danger of contamination from previous dressing of suppurating wounds. Local infections are sometimes met with and are treated by providing drainage, removing surface sutures and swabbing the depths of the wound with tincture of iodin, but where infection becomes generalized to the extent of septic peritonitis, there is little chance for recovery in spite of any resource of science. A carefully executed technic with due regard to asepsis is the most important prophylactic measure to be considered by the veterinarian for this operation.

Hernia.-Hernia may be omental or intestinal. In some cases, a portion of the omentum is included within the margin of the wound and a sufficient particle protrudes causing a slight blemish, and in some few instances causes tension producing pain, which the animal manifestly indicates at different times by its actions. This is evidenced by arching the back and a reluctance to any abrupt or decided movement of the hody. A careful examination of the patient with its abdominal muscles completely relaxed should be made, if possible, and constriction of the omentum may be readily recognized by digital manipulation.

Intestinal hernia may be occasioned by an accidental rent in the peritoneum made in such manner that it is then difficult to approximate margins,-this condition resulting from a lack of care on the part of the surgeon to closely observe the emergency at the time and make provision for perfect coaptation of the divided struetures.

Where hernia exists, either omental or intestinal, animals should be prepared, confined and anesthetized 
as for spaying, and exploratory laparotomy done, exposing the hemial opening, breaking down adhesions if any exist and the wound then closed as has been described in the technique for spaying.

Fventration.-In some cases where the subject has not been bandaged, or where for some reason the wound occasions pain, the animal has been known to remove sutures with the teeth hafore adhesion of the wound margins has taken place. Sometimes eventration results and exposure of a large portion of the intestine and omentum may occur. Such cases are to be handled along gencral surgical principles, the exposed viscera thoroughly eleansed with sterile water or with a normal saline solution, and if not irreparably injuret, the parts are then replaced and the wound again sutured. Some operators use wire sutures in the skin to prevent this occurrence. Cases of eventration are very rare from this cause, however, where a reasonably careful technic has been observed.

Recurrent Estrum.-Recurrence of the estral period after the operation is seen in some cases. It is claimed by some that this condition occurs even when the operation has been properly performed, but we consider this an excuse for the execution of a faulty technic, contending that if every portion of the ovarian tissue is removed, there will be no recurrence of estrum regardless of the age of the animal at the time of the operation.

If post-operative estral periods manifest themselves, it is necessary to do an exploratory laparotomy making a large free incision ample to permit a careful and complete risual examination of the peritoneal cavity. This is done only after all the precautions have been observed as heretofore described for spaying, and a suffi- 
cient amount of broad ligament is then amputated by complete excision; this will insure the complete removal of all remaining ovarian tissue and the recurrent estral periods will subside unless there is in existence degenerative changes involving the uterus or portions of the horns which are usually left. Should this be the cause of manifestation of estrum the symptoms of heat will not be typical, nor will they exist in a marked degree, but in such cases the removal of the diseased structures is indicated. 


\section{CASTRATION OF THE CAT (SPAYING)}

The principal reason for unsexing female cats is to prevent the annoyance occasioned by estrum and its usual culmination in pregnancy with the too frequent reproduction of undesirable offspring.

Age for Operating.-Animals that are in a thrifty condition are best unsexed when about six or eight months of age. However, this operation may be performed when the cat is fully matured and the operation has not proved impractical in subjects grown to five or six years of age. Reason convinces us, though, that the attendant shock would naturally be much greater in animals of advanced years.

Anatomy.-The principal structural differences in the parts directly concerned for the operation of spaying, between the cat and the dog, are that the cat possesses a very thin abdominal wall, longer uterine horns and smaller ovaries. The oviducts and ovaries of the cat are not dissimilar to those of the sow.

Preparation of the Subject.-Food should be withheld for 24 hours and a laxative given. During the preparatory period they should be kept in clean, comfortable. quarters that are quiet and secluded, and prorided with a box of sawdust or sand to encourage normal bowel evacuation.

Restraint.-As has been mentioned in the castration of male cats, these animals should be gently and carefully handled becaus of their peculiarly sensitive or- 
ganism and nervous temperament. Few persons appreciate this finer nature of the cat and its susceptibility to fear and strange enviromment. Females are confined by being rolled in a blanket $\mathrm{or}^{2}$ sheet until completely anesthetized, when they may be supported by means of tapes or bandages, the same as indicated for dogs.

Anesthesia.-For the producing of complete anesthesia which is necessary for spaying, A. C. E. in proportions of one part alcohol, two parts chloroform and three parts ether, constitutes a very satisfactory preparation, and it is desirable to give $1-500$ to $1-250$ grain atropin sulphate one-half hour before giving the anesthesia. Alkaloidal salts of opium when used in sufficiently large dosage to effect narcosis, are too likely to result in over-excitement with more or less delirium. This is, therefore, not to be considered as a satisfactory agent.

Preparation of the Surgical Area.-Laparotomy for spaying may be done either in the median line or in the region of the flank, though the flank route is preferable for the reason that cats are very inactive when subjected to confinement after operating, and generaily assume and retain the position of sternal recumbency. While in this position the constant tension and pressure upon the wound seems to be conducive to necrosis and sepsis, whereas a flank incision is so situated that less strain is brought to bear upon the structures, and little or no pressure is exerted upon the area of surgical invasion.

A liberal area in the flank region is next thoroughly lathered and shaved and the skin dried and painted with tincture of iodin. Coal tar derivatives are to be avoided as antiseptics, as cats are very susceptible to compounds containing cresylic acid. A 1 to 5000 solu- 
tion of chinosol in sterile water makes a very satisfactory working solution.

Technic.-An incision is made downward and forward in the space between the external iliac spine and the last rib, this incision being of sufficient length to

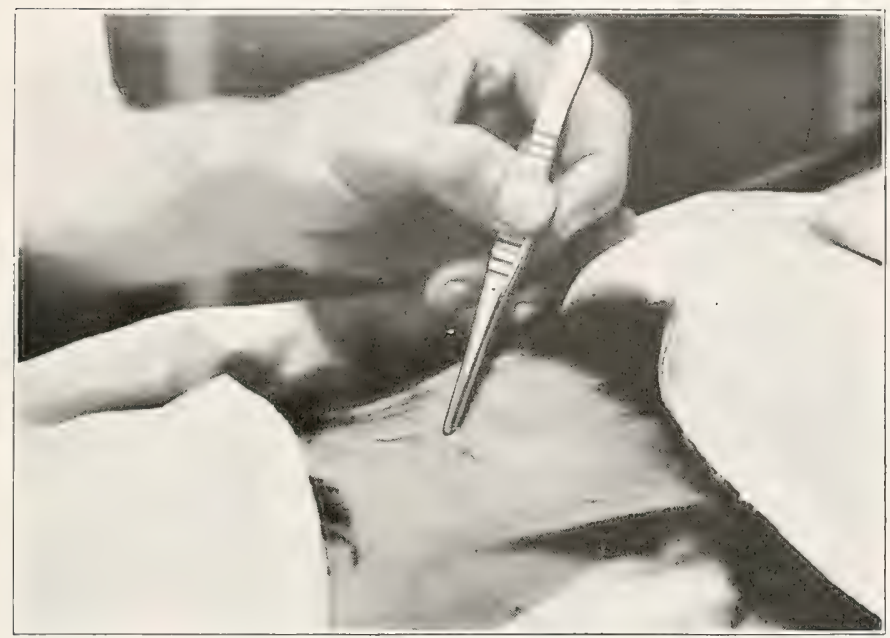

Fig. 23-FLANK INCISION FOR SPAYING THE CAT

permit the retraction of the abdominal wall to ailow a visual examination of the peritoneal cavity. The utmost caution should be exereised in making this incision as the skin and abdominal muscles of the cat are very thin, and to one inexperienced in laparotomy in these subjects, it is easily possible to accidentally wound the viscera by misjudging tissue resistance to the edge of the knife. By retracting the margins of the abdomina] wounds with forceps, one may locate the uterine horn nearest the side of entry which is seized with tissue forceps and brought to the surface. Then, by grasping 
the horn with the fingers and exerting traction upon it, the ovary is readily withdrawn and amputated as has been described for the same operation in female dogs. By retaining the amputated end of the uterine horn and employing traction upon same, the bifurcation of the uterus is brought to view by means of forceps and the remaining horn is removed in like manner. The abdominal wound is sutured by means of a continuous suture including the peritoneum and abdominal muscles. For this purpose No. 00 sterile gut suture material is to be preferred, and the skin and fascia are united by means of another suture of sterile chromic gut, leaving the small opening at the lower commissure for drainage of the wound. The wound is then sealed with flexible collodion with the exception of the small drainage opening which in itself should not exceed one-quarter inch in length. The entire abdominal wall, including the surgical area is then covered with a layer of sterile absorbent cotton to be held in place by means of a sterile gauze bandage which is snugly wound around the subject's body.

After-Care.-The bandage should be removed daily for observation of the wound, and should signs of infection be apparent, the wound secretion may be forced out by gentle manipulation, taking care not to interfere with the primary union of the structures surgically apposed. If no infection occurs and the wound remains almost dry, there is no occasion for the application of antiseptics or the forther molestation of the wound.

It is not uncommon for cats to refuse all food for two or three days or even a week following a major operation, but this in itself does not necessarily constitute an unfavorable symptom. The patients should 
be made as comfortable as possible with respect to temperature, and all excitement should be avoided. It is best to offer them a tempting form of nourishment such as nutritive liquid food,-broths or milkor a little salmon or raw hamburger steak in small quantities. A solid regimen is to be guarded against. As mentioned heretofore for preoperative preparation, provision should be made for the encouragement of urination and defecation by placing within their reach a pan of sawdust or clean sand.

\section{Sequelæ}

Shock.-In singular instances, shock occurs and is manifested by muscular tremors, acceleration of the pulse and irregular respiration, but such disturbance is not likely to attend an ordinary spaying operation. T'o alleviate this condition, applications of external heat and the subcutaneous administration of 1-500 grain each of atropin sulphate and strychnin sulphate will be found beneficial.

Constipation.-Following any major operation, cats are prone to become constipated because of the inactivity due to their natural timidity. Obstinate constipation following laparotomy is often accompanied by wound infection and subcuticular necrosis sometimes involving extensive areas, and in some cases there occurs sloughing of large pieces of skin. A daily examination of the wound should be made to detect early signs of pus and infection, and it should he evacuated surgically before extensive destruction of tissue results. The injection of hydrogen peroxide or solutions of chinosol 1 to 5000 , in the wound, is indicated in these cases. 



\section{APPENDIX}

\section{Equine Umbilical Hernia}

This affection occurs in all animals and with respect to numbers affected, subjects of the equine species rank first among our patients. The nature of this form of hernia is such that veterinarians are frequently asked to treat these cases during the eastrating season. Causes of umbilical hernia may be considered under two classifieations, congenital and occasional or traumatic. Since the proportion of cases that are not congenital is insignificant, the occasional cases will receive no further consideration here.

During intra-uterine life, as soon as the visceral organs have attained considerable size, there is not sufficient room within the splanchnic eavity for all of the viscera. Accommodation of this normally splanchnectopic mass is afforded by the umbilical cord until growth of the abdominal cavity favors a return of the viscera and contraction of the abdominal walls around the umbilicus takes place. In some cases, for reasons not definitely known, there is failure of complete closure of the abdominal walls around the ring, and the result is hernia. Rupture of the umbilical cord usually takes place at its weakest and most constricted part, which, in foals, is about an inch and a half from the body. With rupture of the cord there occurs marked retraction of the ends of the umbilical arteries and some retraction of veins and constriction of the stump 
of the cord. In the normal subject the lumen of the cord is not sufficiently large to permit of hernia. Desiccation and cicatrization of the stump of the cord completes the process of normal spontaneous healing of the navel.

In umbilical hernia the margins of the opening in the abdominal wall is usually somewhat thickened, and in some cases the margin of the peritoneum is firmly adherent to the margin of the abdominal opening. In cases that have been unsuccessfully treated, where clamps or skewers have been employed, considerabla hypertrophy of all tissue surrounding the opening in the abdominal muscles exists. In addition to this there is present more or less fibrous or cicatricial tissue, which renders permanent closure of the abdominal opening difficult in some cases.

Symptoms of umbilical hernia are the presence of fluctuating swelling at the navel, which is usually sufficiently free from adhesions that reduction is easily effected and the margins of the opening are readily outlined by palpation. This may be done by returning the contents of the pouched mass into the peritoneal cavity while the colt is in a standing position. When a subject is placed in dorsal recumbency, spontaneous reduction of umbilical hernia usually occurs, but immediately intra-abdominal pressure is increased by resistance of confinement or straining, the hernial pouch is at once filled with intestine or omentum and it so remains until relaxation of the abdominal muscles and diaphragm occurs.

Umbilical hernia is distinguished from abscess in that abscess remains confined within the bounds of its walls regardless of position assumed by the subject, is therefore not reducible and has no patent communi- 
cating aperture with the peritoneal cavity. In short, the pathognomonic symptom of hernia is the finding of the aperture in the abdominal wall through which temporary reduction of the hemia may be effected.

The course of the affection is essentially chronic and spontaneous recovery is rare. In cases where hernia consists principally of omentum that protrudes through a very small opening, adhesions take place and subsequent atrophy of the impinged structures and contiguous tissue causes a very marked diminution in the size of a previously small enlargement. In other cases spontaneous closure of small hernix results from inflammation probably incited by friction between the contacting parts.

In colts treatment of umbilical hernia is a subject wherein there exists much difference of opinion between veterinary practitioners. The best method of handling any given surgical case is the one which is the least likely to jeopardize the life of the subject and at the same time effect a correction of the existing condition whether pathological or otherwise undesirable.

Some hernix are permanently reduced by the use of improvised trusses with or without the topical application of agents which cause local inflammation. The use of vesicants under cover of trusses or supporting bandages of any sort cannot be too strongly condemned from the standpoint of a surgical consideration of asepsis. When the average improvised truss or bandage is applied it is usually necessary, in order to properly retain it in position, to employ straps or other materials in such manner that pressure necrosis of skin and underlying tissue may result. The writer has observed one case of tetanus where apparently the 
contagium gained entrance by way of abrasions caused by straps and ropes used to hold in place an improvised truss. Such crude methods are certainly inhumane, slovenly and impractical.

Injections of certain agents, such as solutions of silver nitrate, tincture of iodin and oil of turpentine, in the parietes around the umbilical opening result in the production of sufficient inflammation that recovery is brought about in some cases. This method, however, is not dependable. Local applications of nitric acid by means of a glass rod in lines upon the skin or with a swab over and around the hernia produces active inflammation and stimulates recovery in many cases. This method is erude, inflicts much pain to the subject, and may produce excessive sloughing of tissue, eventration and death.

Handling of umbilical hernia along lines that are strictly surgical, is in the majority of cases the very best method of procedure and reduction may be produced by means of skewers, clamos or sutures without doing a herniotomy. Herniotomy is indicated in every case where other means have failed and is preferable in all cases where the hernia is large. Preoperative preparation of the subject is advisable in large colts and necessary where complete anesthesia is to be employed. Preparation consists of withholding all solid or bulky food for 24 hour's.

Restraint of the subject in dorsal recumbency is necessary in all cases, and this is easily accomplished in field work with the harness or ropes. Chloral hydrate may be given per rectum a half hour before operating. or if thought necessary, complete anesthesia may be employed. Where skewers are employed it is advisable to elip away all hair, thoroughly cleanse the 
operative field, dry the surface and paint the skin with tincture of iodin. The operator should have in readiness all necessary equipment, including working solution, silk or linen cord, vulsellum forceps, pincers for amputating points of skewers, scissors and skewers. One may employ ordinary hat pins for skewers as they may be easily and almost painlessly passed through the tissues and are in every way desirable when sterilized. The skin over the most pendent part of the culde-sac is grasped with a pair of vulsellum forceps and as soon as the relaxation of the abdominal wall oceurs, an assistant is instructed to employ sufficient traction by means of forceps that an equal amount of tension is exerted upon all parts of the pouched tissues. It is desirable to tense these structures, enabling the operator to insert the skewers so that they will be situated directly over the hernia and not on one side of it when the animal is in a standing position. "The base of the pouch is grasped and two skewers are pushed through the tissues at right angles with one another and as near the abdominal aperture as possible. This is done with care, after all ectopic structures have been replaced.

A heavy cord is applied above the skewers and the base of the pouched tissues is firmly ligated. An elastic band may be applied over the cord to hasten sloughing of the ligatured mass. The sharp points of the skewers are removed with suitable cutters and the operation is completed. No special after-care is required and sloughing of the strangulated mass takes place in from one to three weeks. In some few instances, because of desiccation of tissue, considerable loal infection and suppuration may ensue, necessitating removal by torsion and traction, the tardily seques- 
trating, pendent mass. Such cases need some local treatment for a week or ten days.

This method of handling umbilical hernia is especially indicated in cases where the abdominal opening is nearly circular in shape and not too large. It constitutes a very safe and practical means of handling hernia of colts eighteen months of age or less.

Clamps have a field of usefulness in certain cases where there exists an oblong opening in the abdominal wall and a laparotomy is thought inadvisable. There are many patterns of clamps employed, but all are calculated to bring about the same effect upon the tissues that are confined within their grasp.

The same general technic is employed in the application of clamps as in the use of skewers. The base of the pouched skin and fascia is grasped and the clamps are applied as closely as possible to the abdominal wall and this directly over the central part of the hernia.

Care should be exercised that too much pressure is not exerted upon the tissues in large hernix, that early sloughing and possible eventration may be avoided. Some clamps are so constructed that they may be in part supported by straps which encircle the body of the subject. This affords a means of preserving the clamps when the tissues have sloughed, but necessitates careful confinement of the subject lest the clamp be prematurely dislodged by the girth or support being caught upon fences, walls, etc.

Herniæ, umbilical and abdominal, have been reduced by means of sutures such as the cobbler's stitch, or mattress sutures. The principle of this method consists in effecting apposition of tissues in a manner similar to that done by clamps. The sutures are passed 
through and through all tissues at the base of the diverticulum in such a manner that the entire mass is comprised within the grasp of the sutures which really constitute multiple ligatures.

Where herniotomy is to be done, general anesthesia with chloroform is necessary. The field of operation should be carefully cleansed, shaved, dried and painted with tincture of iodin, and a large sterile towel or cloth placed over the abdomen with an opening of sufficient size made in it to expose the hernia. An elliptical pice of skin and underlying fascia or other tissue is then removed in just enough quantity to allow perfect apposition of the skin with sufficient tension to reinforce the structures underneath.

The opening exposes to view the margins of the abdominal aperture. If much cicatricial tissue resulting from previous interference exists, it may be necessary to remove some of it with a sealpel or with heavy dissecting scissors. If the opening is circular, it is advisable to remove a triangular portion of the marginal structure at the anterior and posterior parts, making the opening near oval and permitting of more nearly perfect approximation of the margins. Scarification of the edges of the opening serves to increase local inflammation and promote early adhesion of the joined tissues.

Apposition of the margins of the subeuticular opening by means of interrupted sutures of heavy chromic gut or silk is effected. The sutures are set well back of the margin and include peritoneum and all muscular structures. Tincture of iodin is applied to the sutured tissues and the skin and fascia are joined by mattress sutures of heavy silk. With careful technic, primary union results. 
After-care consists in the restriction of violent exercise in adult horses and avoidance of large quantites of bulky food. Subjects are allowed the freedom of pasture and are turned out and allowed to exercise at will. Where they are kept away from the stables and lots, no after-care is required. In the spring and summer months, where this work can be done away from contaminated stables and sheds, there is practically no danger from infection if care is taken to execute a reasonably good surgical technic. 


\section{CESAREAN SECTION IN THE SOW}

When performed at the right time, there are few operations that are productive of proportionately greater profitable results than this. In every community where hog raising is conducted there are certain seasons when dystokia in sows is very prevalent, and in many instances it is not to be ascribed to mismating or to any one definite causative factor. In the experience of every general practitioner in such localities, there are times when his skill and patience are frequently tried in handling cases of dystokia where he is undecided as to the feasibility of doing the cesarean operation. When he does decide to operate as a last resort and the result is unsatisfactory because of long protracted labor or septicemia occasioned by injuries to the vaginal and uterine membranes, inflicted with various appliances in the hands of laymen in their attempts to deliver the fetus, he is apt to view the situation, as frequently do his clients - that the cesarean operation in the sow is impracticable. When this operation is performed as soon as it is evident that serious dystokia is in existence and when the genitalia have not been injured and infected as a result of manipuIation with obstetrical instruments, recovery should obtain in at least 75 per cent of the cases operated upon.

Indications for operating are cases of dystokia where active labor is not productive of delivery within 12 to 18 hours after travail has begun. As soon as it is evident that serious dystokia exists in any given case, 
there is every reason for operating early, and deferring the operation until uterine atony and beginning degenerative changes have taken place, lessens the chances of recovery. As a rule swine withstand laparotomies very well, and the cesarean operation should be performed more frequently than it is in veterinary practice, and when performed should be done early.

Anatomy.-There exists no essential difference in the anatomy of the abdominal wall in the region anterior to the external iliac spine from that of the horse, except that in sows there is usually found a heavy layer of fat interposed between the subcuticular fascia and the external oblique muscle, and the musculature of this region is proportionately less vaseular than in the horse.

The uterus and its horns are supported by an abundantly large, broad ligament. The body of the uterus is very short and serves merely as a passageway between the horns and the vaginal canal. The uterine horns are very long and necessarily tortuous, and it is possible to bring any part of the horns to the surface of an abdominal incision without difficulty.

Anesthesia.-The problem of anesthesia in this work is one which has been given considerable thought by operators because they have learned from experience that many sows do not readily withstand the effect of chloroform, frequent losses being directly due to chloroform poisoning. Dilutions of chloroform such as A.C.E. in proportion of one part of alcohol, two parts chloroform and three parts of ether, constitute a very satisfactory agent for the production of anesthesia in selected cases. Subjects that have been bred, fed and otherwise cared for so that they have matured early, are apparently more susceptible to untoward results occasioned by inhalation anesthesia. 
Rectal administration of chloral hydrate in dilutions of one part of chloral hydrate to 12 parts of tepid water, given in quantites of one drachm for each 100 pounds weight, will produce sufficient stupefaction to enable the surgeon to do a satisfactory operation. In a few cases a solution of chloral hydrate is not retained, even when diluted with 16 parts of water. This may be due to a supersensitive rectal mucosa or a lax sphincter ani, and difficulties so encountered may be overcome by clamping the anus with a pair of forceps, thus preventing escape of the solution of chloral hydrate until a marked anesthetic effect is evident. Is soon as there is sufficient soporific effect manifested the forceps should be removed to permit evacuation of the contents of the rectum, and in cases where it would seem neeessary, the employment of an enema for the removal of any excessive amount of chloral hydrate is advisable.

Restraint.-If possible, the subject is placed upon some sort of improvised operating table (a barn door supported by tressels or boxes answers the purpose very well) and "hog tied" leaving either the right or left flank exposed for surgical invasion.

Equipment.-One should have at hand sterile towels or sheets, two or three curved needles threaded with silk, three or four curved cambric pointed needles threaded with No. 1 chromic gut, a scalpel, Kelley forceps, six or eight pairs of 8 or 10 inch compression forceps, scissors, absorbent cotton, sterile gauze, and a basin containing any suitable antiseptic solution such as a one per cent solution of Liquor Cresolis Compositus.

Preparation of the Field of Operation.-The hair should be clipped from a liberal area in the region 
just posterior to the last rib, and the skin may be cleansed with a swab and gasoline and then painted with tincture of iodin.

Technic-An incision is made in the space between the external iliac spine and last rib, the direction of which is to be downward and forward and of sufficient length to permit comfortable access for manipulation of the parts to be dealt with. All of the tissues comprising the abdominal wall are divided with a scalpel, and hemorrhage, if of any consequence, is controlled by means of forceps. The flank of the subject is now covered with sterile towels and kept so until the operation is completed.

The hand is introduced into the peritoneal cavity, and by palpation it is determined whether one or both horns are gravid and whether a fetus is lodged, in part, in the body of the uterus. A horn (the one nearest the abdominal incision if it is gravid), is grasped and brought to the surface by gentle traction. At this time it is necessary to carefully examine the parts for the purpose of determining whether a hysterotomy or a hysterectomy is to be performed.

If there exists evidence of considerable emphysema of the fetuses indicating that degenerative changes involving the uterine horns have taken place, amputation of the uterus and horns should be decided upon. If both horns are gravid and particularly if more than one fetus is contained in each horn, hysterectomy should be done; it is very difficult to do a hysterotomy in such instances without producing laceration of some part of one or both gravid horns with probable contamination of the peritoneal cavity oceasioned by escaping putrid fluids.

Where hysterectomy is decided upon the gravid horn 
nearest the site of incision is entirely withdrawn from the peritoneal cavity, and the broad ligament anterior to the ovary is clamped with a pair of forceps. Another forcep is securely clamped near the ovary, and division of tissues between the two forceps is effected with the scissors, and by carefully tearing the attachment of the broad ligaments, the end of the gravid horn is removed from the peritoneal cavity.

The next step in the operation consists in causing the evacuation of the contents, if any, of the body of the uterus. This is done by a process of squeezing or milking out by digital manipulation. This having been done, two pairs of heavy forceps are securely clamped upon the body of the uterus with a space of about one inch intervening, and the body of the uterus is divided between the two pairs of forceps, thus permitting the removal of the bifurcated portion of the uterus which is held firmly closed by means of forceps. Repeating the process of rupture of the broad ligament by tearing or blunt dissection, progressing in the direction of the ovary along the horn farthermost from the opening in the abdominal wall, this horn is traced out to a point beyond the location of the ovary, and two pairs of forceps are clamped upon the broad ligament anterior to the location of the ovary, and the remioval of the horn, oviduct and ovary is effected as has been previously described.

The amputated ends of the broad ligaments are ligated by means of a gut suture proximal to the position of the forceps, and they are then removed. The end of the stump of the uterus is lifted, by means of the forceps attached thereto, as nearly as possible to the surface of the abdominal wound, and its mucous lining is painted with tincture of iodin. The stump of 
the uterus is then ligated by means of a heavy gut or silk thread which is retained in situ by being fixed at several points with a needle and securely tied. This having been done, the forceps attached to the uterus are removed, and the abdominal wound is ready to be sutured.

The peritoneum and muscular layers of the abdominal wall are approximated by means of a continuous suture using gut or silk thread. The skin is united by means of a heavy silk or linen suture material, using a continuous suture, and the parts are painted with tincture of iodin and immediately coated with a layer of pine tar.

Indications for the performance of hysterotomy are in cases where only one uterine horn is gravid, or, if both horns are gravid, where living fetuses are contained in them, and there exists no apparent structural change involving the body of the uterus and cornua -in cases where labor has not existed for more than 24 hours and where the mucous membrane of the genitalia has not been seriously injured by means of instruments in attempting delivery.

If both uterine horns are gravid, the one nearest the abdominal opening should be brought to the surface and laid upon towels which line the wound margins and cover the surface of the body of the subject. An incision is then made through the body of the horn at a point rather near its dorsum. If there are severa] fetuses contained within this uterine horn, an incision is made over the body of the fetus lying nearest the uterus. The incision should be made parallel with the long axis of the uterine horn and of sufficient length to permit the easy removal of the fetus.

After having removed the fetus, taking care not to 
permit the escape of fluids which would contaminate the abdominal wound or possibly the peritoneum, the remaining fetuses are removed by way of the same ineision. This is accomplished by digital manipulation of the horn, - an assistant is of much help at this stage of the operation, - and after having evacuated the contents of this horn, the other one is brought to the surface. If possible its contents are crowded out and by gentle manipulation the fetuses are extracted by way of the incision first made.

If attachment of the placental membranes preveiits the transferring of the contents of the second horn across and by way of the body of the uterus through the first horn and out through the incision made therein, it is necessary to make a second opening for the purpose of removing the fetuses directly out of the horn in which they are contained.

After having removed all fetuses, any portions of fetal membranes are carefully removed, and by means of dressing forceps and cotton the interior of the uterine horns and the body of the uterus are carefully swabbed, removing, if possible, all of the contents. This having been accomplished, the two incisions made into the horns of the uterus are closed, using for this purpose chromic gut and uniting the wound margins with a Lembert suture.

After having mopped the wound margins with pledgets of cotton taken from the working solution, the uterus and horns are returned into the peritoneal cavity, and the wound margin is likewise cleansed of any possible contaminating materials and sutured as just described in hysterectomy.

After-Care.-In some cases there is marked evidence of shock following a cesarean operation, and a hypo- 
dermic injection of 1-100 to 1-50 grain of atropin sulphate is beneficial. Animals should be placed in comfortable quarters and unmolested for a few hours until they have had time to recover from all shock incident to the operation. They should be given water ad libitum and offered a gruel of oil meal, shorts and water or other suitable nutritive and laxative food. No special after-care is necessary except to give the subjects every attention to make them as nearly comfortable as possible.

If pigs are delivered in a condition to survive, they are best taken away from the sow for six or eight hours, after which time they may be returned, and if the case progresses favorably, she can nurse them almost as well as though normal delivery had taken place. 


\section{INDEX}

Abdominal cryptorehidy. . 36 Accidents from restraint ..........21, 19

After-care of bulls ......66 66

After-care of calves ....6 $6 \pm$

After-care of colts ..... 32

After-care in eaponizing.. 88

After-care of eats ...... 85

After-care of cat in spaying ............122

After-care of cryptorehids 45

After-care of dogs ...... 85

After-care of dog in spaying ..........113

After-care of heifers .... 99

After-care of inguinal eryptorehids ......... 47

After-care of mares ..... 94

After-care of sheep ..... 73

After-care of stallion ....34

After-care of swine ..... 76

Age for calves ......... 11

Age for castrating ...... 11

Age for eats .......... 12

Age for colts ........... 11

Age for cryptorchid castration .............37

Age for dogs .......... 12

Age for heifers ........ 12

Age for sheep ......... 12

Age for swine .......... 12

Anesthesia .......... 17

Anesthesia in eastrating eryptorehids .........4 40

Anesthesia in castration of mares ............. 90

Anesthesia of eat ...83, 120

Anesthesia of cow ....... 95

Anesthesia of $\operatorname{dog}$....83, 105

Anesthesia of sow ......134

Anesthesia of stallion ...33
Anesthesia of swine .... 80

Atrophies following restraint ...........49 49

Birds, eastration of..... 87

Bos, castration of....... 59

Bulls, after-care of .....6 66

Bulls, castration of ......64

Bulls, eastration sequelæ of $\ldots \ldots \ldots \ldots \ldots \ldots 68$

Bulls, contamination by flies ............. 71

Bulls, eryptorehid ..... 66

Bulls, infection of wounds in $\ldots \ldots \ldots \ldots \ldots \ldots$. 70

Bulls, internal hemorrhage of $\ldots \ldots \ldots \ldots . \ldots 69$

Bulls, restraint of.......64 64

Bulls, serotum of ....... 59

Calves, after-care of..... 64

Calves, age for.......... 11

Calves, eastration of..... 62

Caponizing ........... 87

Caponizing, after-care in.. 88

Care in restraint........ 20

Cats, after-eare of...... 85

Cat, after-care of in spaying ................. 122

Cats, age for.......... 12

Cat, anesthesia of.... 83, 120

Cats, eastration of.......8 83

Cat, castration of female. 119

Cat, constipation following spaying of ...........123

Cats, eryptorehidy in.... 85

Cat, shock following spaying of .............123

Cesarean section in sow...133

Charlier's method in eows. 95 
Charlier's method in mares 89 Clamps ............. 25 Cold affecting subject.... 13 Colic from eastration..... 51 Colts, after-care of....... 32 Colts, age for.......... 11 Colt, normal .......... 29

Conformation, effect upon. 10 Constipation following spaying of cat........123

Covered operation.....28, 48

Covered operation, modification of ............ 31

Cow, anesthesia of....... 95 Cows, Charlier's method in 95 Cow, vaginal ovariotomy of 95 Cryptorchids, after-care of 45 Cryptorchids, anatomy of. 37 Cryptorehids, anesthesia in castrating ......... 40

Cryptorehid bulls ....... 66

Cryptorehid castration, age for ............ 37

Cryptorehid horses, eastration of ........... 35

Cryptorchids, inguinal ....44 46

Cryptorehids, laparotomy for eastrating .......444

Cryptorchids, preparation of .............. 39

Cryptorchid restraint..... 39

Cryptorehids, surgical technic for castrating......4 41

Cryptorehidy, abdominal. . 36

Cryptorchidy of bull, interstitial ........... 68

Cryptorchidy in cats..... 85

Cryptorehidy in dogs.... 85

Dogs, after-care of...... 85

Dogs, after-care in spaying ................113

Dogs, age for eastrating.. 12

Dogs, anesthesia of...83, 105

Dogs, eastration of...... 83

Dogs, eryptorchidy in..... 85

Dogs, eventration in.....117

Dogs, hemorrhage in.....115

Dogs, hernia in ........116

Dogs, postoperative infection in.............115

Dogs, reeurrence of estrum in $\ldots \ldots \ldots \ldots \ldots . \ldots 117$
Dogs, sequelæ of spàying

in ...............114

Dogs, spaying of........103

Ecraseur ........... 25

Effect of rain on subject.. 13 Effect of filth on subject.. 13 Emaseulator ........... 25 Equine umbilical hernia...125 Estrum in dog, recurrence of $\ldots \ldots \ldots \ldots \ldots \ldots \ldots 17$

Eventration in dog......117

Filth affecting subject.... 13 Fistula, serotal......... 53 Flesh, character of modified 10 Fractures from restraint.. 48

Heifers, after-care of.... 99 Heifers, age for castrating 12 Heifers, eastration of.... 97 Heifers, restraint of.....997 Hemorrhage .......... 49 Hemorrhage of bulls, intermal ............ 69

Hemorrhage of dogs..... 115

Hemorrhage of stallion... 35

Hemorrhage, primary .... 49

Hemorrhage, secondary .. 50

Hemorrhage, treatment of. 50

Herniæ .........47, 52

Hernia, equine umbilical..125

Hernia in $\mathrm{dog} . . . \ldots \ldots . .116$

Hernia of swine, extra-vaginal .............. 79

Hernia of swine, intra-vaginal ........... 79

High flankers .......... 46

History ............ 9

Horse, eastration of..... 29

Hydrocele ........... 56

Hydrocele, prevention of. . 31

Hydrocele, treatment of... 57

Infection in dog, postoperative .............115

Infection of wounds in bulls ............ 70

Inguinal cryptorchids..... 46

Inguinal cryptorchids, after-care of........4 47 
Instruments ......... 15

Instruments, care of..... 16

Interstitial eryptorehidy of bull

Laparotomy for castrating cryptorehids .........44 44

Ligatures ........... 25

Mares, after-care of..... 94

Mares, anesthesia in eastration of ......... 90

Mares, eastration of..... 89

Mares, Charlier's method in .............. 89

Mares, preparation of.... 90

Mares, restraint of ......990

Mares, technic of operation in $\ldots \ldots \ldots \ldots \ldots \ldots 91$

Milk, effect upon....... 10

Normal colt, eastration of. 29

Object $\ldots \ldots \ldots \ldots \ldots \ldots .9$

Ovariotomy of cow.......995

Peritonitis .......... 54

Preoperative preparation of stallion........... 33

Preoperative preparation of subject........... 13

Preparation of eryptorehid subject ............ 39

Preparation of mares.... 91

Preparation of surgical area .............. 14

Reasons for eastrating.... 9

Restraint.......17, 18, 20

Restraint, accidents from ..........21, 48

Restraint, atrophies following $\ldots \ldots \ldots \ldots \ldots, 49$

Restraint, care in....... 21

Restraint, fractures from.. 48

Restraint of eryptorchids. 39

Restraint of heifers...... 97

Restraint of mares....... 90

Restraint of stallions.... 33

Restraint of swine...... 75
Scirrhus cord ......... 54

Scirrhus cord in swine... 77

Scirrhus cord, treatment of 55

Scrotal fistula ........ 53

Scrotal hernia........47,79

Scrotum, anatomy of..... 23

Scrotum of bull........ 59

Serotum, swelling of..... 52

Season for castrating..... 12

Sequelæ $\ldots \ldots \ldots \ldots \ldots .48$

Sequelæ of castration in bulls .............6.68

Sequelæ of castration in sheep ............. 74

Sequelæ of eastration in stvine ............ 77

Sequelæ of spaying in dogs ................114

Sheep, after-care of...... 73

Sheep, age for eastrating.. 12 Sheep, castration of..... 73

Sheep, sequelæ of castration in............ 74

Shock .............. 51

Shock following spaying of cat ..............123

Solution basins......... 17

Sow, anesthesia of.......134 Sows, eastration of.......101 Spaying of female eat....119 Spaying of eow ........ 95 Spaying of female dog....103 Spaying of heifers ...... 97 Spaying of mare ........ 89 Spaying of sows .........101 Spermatic cord, anatomy of 23 Stallion, after-care of.... 34 Stallion, anesthesia for.... 33 Stallion, castration of... 32 Stallion, hemorrhage in... 35 Stallion, preparation of... 33 Stallion, restraint of..... 33

Standing castration...... 18 Surgical area, preparation of $\ldots \ldots \ldots \ldots \ldots \ldots 14$

Surgical technic for castrating eryptorehids...... 41

Swelling of serotum..... 52

Swine, after-care of..... 76

Swine, age for castrating. 12

Swine, anesthesia of..... 80

Swine, castration of..... 75 
Swine, extra-vaginal hernia of ............. 79

Swine, intra-vaginal hernia of ............. 79

Swine, restraint of...... 75

Swine, seirrhus cord in... 77

Swine, serotal hernia in... 79

Swine, sequelæ of castration in............ 77

Testicle, anatomy of:.... 23 Testicles, comparative size of .............. 24 Torsion .............25

Treatment of hemorrhage. 50 Treatment of hydrocele... 57 Treatment of scirrhus cord 55

Uncovered operation....27, 76

Teehnic of operation in mares

Vaginal tunies ........ 23

91 Young calves, castration of 59 





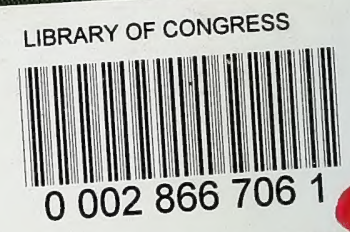

